\title{
Review on Autoimmune Reactions in Female Infertility: Antibodies to Follicle Stimulating Hormone
}

\author{
Kadri Haller-Kikkatalo, ${ }^{1,2,3}$ Andres Salumets, ${ }^{2,3}$ and Raivo Uibo ${ }^{1,3}$ \\ ${ }^{1}$ Department of Immunology, Institute of General and Molecular Pathology, University of Tartu, Ravila Street 19, \\ Biomedicum, Tartu 50411, Estonia \\ ${ }^{2}$ Department of Obstetrics and Gynecology, University of Tartu, L. Puusepa 8, 51014 Tartu, Estonia \\ ${ }^{3}$ Competence Centre on Reproductive Medicine and Biology, Tiigi 61b, Tartu 50410, Estonia
}

Correspondence should be addressed to Kadri Haller-Kikkatalo, kadri.haller-kikkatalo@ut.ee

Received 27 May 2011; Accepted 3 August 2011

Academic Editor: Gilbert Faure

Copyright () 2012 Kadri Haller-Kikkatalo et al. This is an open access article distributed under the Creative Commons Attribution License, which permits unrestricted use, distribution, and reproduction in any medium, provided the original work is properly cited.

Female fertility can be affected by diseases or dysfunctions of reproductive tract, neuroendocrine system, and immune system. Reproductive autoimmune failure can be associated with overall activation of immune system or with immune system reactions specifically directed against ovarian antigens. Majority of the antiovarian autoantibodies are directed against $\beta$-subunit of follicle stimulating hormone (anti-FSH). This paper summarizes a current clinical classification of female infertility in the context of general activation of autoimmunity and antiovarian autoimmunity by describing serum anti-FSH. The presence of naturally occurring anti-FSH in healthy women will be discussed. In addition, the putative impairment of ovarian folliculogenesis in case of increased production of those antibodies in infertile women will be characterized.

\section{Introduction}

Infertility is a condition that affects a couple and is defined as the lack of conception after an arbitrary period of 12 months without using any contraception [1]. These couples comprise the infertile and the sterile members of the population, for whom is no possibility of natural pregnancy, and the remainder who are subfertile [2]. The latter inadvertently includes normal fertile females who failed to conceive by chance during the 12 or 13 opportunities a woman has per year [1]. Infertility contributes a great proportion to overall reproductive ill health, since there are $\sim 60-80$ million infertile couples ( $\sim 15 \%$ of couples) around the world [2]. Minor fertility impairment is seen in both partners more frequently than expected ( $>70 \%$ of infertile couples) [2]. Although infertility per se may not threaten physical health, it may have a serious impact on the mental and social well-being of couples and may result in detrimental social consequences, such as divorce or ostracism [2]. In addition, infertility contributes to low birthrate, which is a major social and national issue in developed countries.
Infertility represents an increasing medical problem. A progressive decrease in fertility rate has been indicated since 1955 [1]. The decrease is associated with both medical and nonmedical factors. Women's age is the major determinant of the average time required to conceive. The highest live birth rates are in the age group of 25-30 years and declines sharply after the age of 35 [3]. Also, the duration of infertility contributes meaningful information to the estimation of future fertility [4]. Chromosomal aberrations, monogenic diseases, endocrine dysfunctions, sexually transmitted diseases (STDs), and immune system dysfunctions are medical situations, which can contribute both to male and female infertility. Unfortunately, still in about $10 \%-20 \%$ of couples, the infertility cause remains unknown [2]. However, autoimmune mechanisms may be the case in those couples and have been associated with premature ovarian failure (POF), "subclinical" ovarian failure and with recurrent pregnancy loss [1].

Nowadays, when the utilization of assisted reproduction technologies has improved the prospects of infertility treatment, still every second infertile couple seeks for 
medical advice [2]. First child following in vitro fertilization (IVF) was born in 1978 [5]. Today, approximately 2.5\% of newborns account for IVF-treated couples in European countries, which remains somewhat lower when compared to Nordic countries [6]. Regardless of constant improvement of pregnancy rate in IVF, the success rates are still around $30 \%$ per cycle [6]. Autoimmunity and the presence of autoantibodies have been invoked as a possible mechanism of IVF failure. There are contradicting data regarding the importance of certain antibodies to damage directly the preimplantation embryo, interfering with implantation process or formation of placenta [7-11]. Consequently, the overall activation of the immune system in female infertility has been suggested [12].

For the purpose of improving infertility treatment, the mechanisms of immune system associated with natural reproduction as well as with infertility should be carefully evaluated. This paper summarizes a current clinical classification of female infertility in the context of general activation of autoimmune processes and antiovarian autoimmunity by describing serum antibodies to follicle stimulating hormone (FSH).

\section{Autoimmunity}

Active tolerance mechanisms are required to prevent inflammatory responses to the many innocuous air-borne and food antigens that are encountered at mucosal surfaces. However, the most important aspect of tolerance is self-tolerance, which prevents the body from mounting an immune attack against its own tissues-prevention from autoimmune reactions. Autoimmunity is associated with a dysbalance of various components of the immune response and with the development of autoantibodies directed against normal host antigens. The susceptibility to autoimmune reactions is regulated at several levels [13]. The proliferation of mature T-lymphocytes in response to either self- or foreign antigenic stimuli is affected by the nature and strength of antigenic peptide-MHC (major histocompatibility complex) stimulation [13, 14]. Human leukocyte antigen (HLA)-class II molecules influence the stability of the antigenic-peptideHLA complex in an allele-specific manner, affecting the induction of central tolerance [13]. As revealed by the studies on anti-insulin autoimmunity, the stimulation provided by antigenic peptide-MHC stimulation could also be modulated by genetic variations of the insulin gene, influencing the gene expression in the thymus $[15,16]$. Tissue-specific autoimmunity appears to be additionally dependent on local factors, including infection-related tissue damage [13], iatrogenic manipulations [17], and the level of autoantigen in periphery $[18,19]$. Thus, the expansion of cells responding to low-affinity ligands (self-antigen) or anomalies in the deletion of high-affinity autoreactive T-cells can lead to autoimmune reactions [14]. Once an autoimmune disease has been developed, a wider range of autoimmune reactions may progress, meaning that an individual may develop more than one autoimmune disease [20].

\section{Reproductive Autoimmune Failure in Women}

Female fertility is regulated by a series of highly coordinated and synchronized interactions in the hypothalamicpituitary-ovarian axis. Therefore, female fertility can be affected by diseases or dysfunctions of reproductive tract, neuroendocrine system, and immune system or by any severe or exhausting general disease. The etiology of female infertility in a diagnostic and treatment point of view is summarized in Table 1 (based on the guidelines provided by $[1,2])$. The reproductive autoimmune failure syndrome was originally described by Gleicher et al. in women with endometriosis, infertility and increased autoantibodies [21]. Autoimmune mechanisms as well as an increased production of multiple autoantibodies are involved in such infertility disorders as POF, endometriosis, polycystic ovary syndrome (PCOS), unexplained infertility, and repeatedly unsuccessful IVF attempts and may be responsible for the pathophysiology of preeclampsia or spontaneous abortions, as stated in many original articles as well as discussed in reviews (Table 2) [19, 22-25]. Although not many studies have been performed on humans, the role of cellular immunity in ovarian autoimmunity, in addition to humoral immunity, has been detected both locally in the ovary [26] as well as in periphery [27]. However, due to the technical difficulties in everyday laboratory work, most clinical studies are restricted to detecting serum antibodies in order to define autoimmune activation in a patient.

In Western Europe and North America, where tubal diseases are relatively uncommon, endocrine dysfunctions can be identified in about $10 \%-20 \%$ of women presenting with infertility [28]. Most common cause for hypergonadotropic hypogonadism is POF [1]. POF is defined as secondary amenorrhea with elevated gonadotrophin levels observed under the age of 40 and affect $1 \%-2 \%$ of women of the general population [1]. POF is highly heterogeneous condition and can be associated with autoimmune disorders, ovarian surgery, iatrogenic causes such as chemoradiotherapy, systemic diseases such as galactosaemia, or with genetic factors [1]. In more than half of the cases, the development of POF has been associated with autoimmune reactions to ovarian tissue $[29,30]$. An investigation of antiovarian autoimmune reactions and autoantibodies may be severely hampered by the fact that POF represents an end-stage of disease. By the time when the disease in a women is diagnosed, she has exhausted her follicular supply and, presumably, also the target antigen for the autoimmune attack on her ovary. Thus, the autoimmunity causal of POF can be difficult to detect retrospectively. Regardless of that, high prevalence of antiovarian antibodies (AOA) $(30 \%-67 \%)$ and others organand nonorgan-specific autoantibodies have been observed in patients with POF $[29,31,32]$.

Normogonadotropic anovulation represents about 50\% of women with an endocrine cause of infertility and includes mostly the patients with PCOS. PCOS affects up to $4 \%-$ $10 \%$ of all women of reproductive age $[33,34]$. PCOS is characterized by polycystic ovaries, oligoanovulation, insulin resistance, and hyperandrogenism or hyperandrogenaemia $[35,36]$. Infertility in PCOS is associated with an alteration in 
TABLE 1: Etiology of female infertility (based on the diagnostic and treatment guidelines provided by $[1,2])$.

\begin{tabular}{l}
\hline Anovulatory infertility \\
\hline Hyperprolactinaemia \\
Pituitary adenoma \\
Hypogonadotrophic hypogonadism \\
Kallmann's syndrome \\
Weight loss \\
Hypergonadotropic hypogonadism \\
Premature ovarian failure (POF) and early menopause \\
Gonadotrophin resistance due to a receptor defect \\
"Normogonadotropic" oligoanovulation \\
Polycystic ovary syndrome (PCOS) \\
Adrenal cause of hyperandrogenism \\
Genetic determinants \\
Turner syndrome, Swyer syndrome \\
Androgen insensitivity syndrome \\
Androgen synthesis disorders \\
\hline Tuboperitoneal infertility \\
\hline Tubal factor infertility \\
Endometriosis \\
\hline Autoimmunity \\
\hline POF \\
Recurrent pregnancy loss \\
Autoimmunity-associated infertility \\
\hline Uterine abnormalities \\
\hline Malformations \\
Eubmucous myomas \\
\hline Unexplained infertility \\
\hline
\end{tabular}

folliculogenesis and in the selection of the dominant follicle leading to anovulation [37]. An autoimmune mechanism has also been suggested in some cases of PCOS, where increased prevalence of AOA and common organ- and nonorganspecific autoantibodies has been detected [19, 22, 25].

Tubal factor infertility accounts for $10 \%-30 \%$ in developed countries and up to $85 \%$ in developing countries of reported cases of infertility [38]. Decreased fecundity may be attributed to impaired ovum transport due to fimbrial damage and/or adnexal adhesions. The factors responsible for tubal disease are diverse and include infections, pelvic surgery, and endometriosis. Pelvic inflammatory disease (PID) represents the link between STD and infertility. In majority of cases, acute PID results from acute bacterial endometritis and salpingitis. Most of the long-term consequences of PID, however, stem from the destruction of normal tubal structure, with or without tubal occlusion [1]. While in developed countries, there has been a decline in the incidence of STD salpingitis and correspondingly in PID by the end of 1980s, a significant rise of STD in Eastern Europe and central Asia, has been documented at the beginning of $1990 \mathrm{~s}[2,39,40]$. The incidence of infertility following the acute PID depends on various factors and varies from $6 \%$ to $60 \%$ [1]. In addition, there is a silent, relatively asymptomatic PID, which could be the case in up to $80 \%$ of chlamydial infections [41]. Genital infection of Chlamydia trachomatis is currently the most common bacterial STD (in 20\%-40\% of cases) and it coexists with the infection of Neisseria gonorrheae in $25 \%-50 \%$ of cases [1]. Manifestation of tubal destruction, however, is dependent also from the ability to activate autoimmune inflammation. During chlamydial infection, similar to most infections, the synthesis of heat shock proteins (HSPs) is strongly upregulated. HSPs are the major antigens and can induce a strong immune response [42]. Because there is a strong amino acid sequence homology between microbial and human HSPs, the induced immune response against microbial HSPs may incite an autoimmune inflammatory reaction in the host, culminating in tubal damage $[42,43]$.

Endometriosis is characterized by the growth of endometrial tissue outside the uterine cavity. It is a common disorder, affecting $10 \%-20 \%$ of all women of reproductive age [44, $45]$. The most frequent clinical presentations of endometriosis include dysmenorrhea, pelvic pain, dyspareunia, infertility, and pelvic mass. In addition to distorted pelvic anatomy, altered peritoneal function, impaired implantation, and endocrine and ovulatory abnormalities, the alterations in humoral and cell-mediated immune system reactions contribute to the endometriosis-associated female infertility [46]. Moreover, endometriosis has been labelled an "autoimmune syndrome". Classical autoimmune diseases, as well as endometriosis, are characterized by polyclonal B-cell activation and production of multiple different autoantibodies [21]. About $40 \%-60 \%$ of patients with endometriosis have elevated autoantibody titers when tested against a panel of autoantigens [47]. They often possess specific antiendometrial antibodies $[43,48,49]$, but also AOA, antinuclear autoantibodies (ANA), smooth muscle autoantibodies (SMA), and antiphospholipid antibodies (APA) [23, 50, 51].

Approximately $10 \%-20 \%$ of couples who are unable to conceive are determined to have unexplained infertility [2]. Unexplained infertility is a term applied to an infertile couple whose standard investigations (semen analysis, tubal patency, and laboratory assessment of ovulation) yield normal results. A longer period has been suggested to be required for this group of patients to achieve pregnancy without treatment, as $70 \%$ of fertility rate is achieved in two years for the group of unexplained infertility, whereas only nine months are required for the fertile group to achieve the same rate [52]. However, about $20 \%-30 \%$ of these patients remain infertile even after 9 years of attempting to conceive [53]. Therefore, unexplained infertility appears to represent either the lower extreme of normal distribution of fertility, or it arises from a defect in fecundity that cannot be detected by the routine infertility evaluation $[2,54-56]$. Dysregulation in immune system reactions with enhanced production of autoantibodies is putative etiologic candidate for this group of patients $[32,57,58]$.

Thyroid autoantibodies have been associated with recurrent pregnancy loss, POF, and repeatedly unsuccessful IVF attempts $[11,59,60]$. This is hypothetically explained by the fact that organ-specific autoimmune diseases, like 
TABLE 2: Serum autoantibodies in female infertility and infertility-related diseases.

\begin{tabular}{|c|c|c|c|c|}
\hline Patients $(\mathrm{N})$ & Autoantibodies & Methods & $\begin{array}{l}\text { Study } \\
\text { design }\end{array}$ & Authors (reference no.) \\
\hline \multicolumn{5}{|c|}{ POF } \\
\hline POF (45) & $\begin{array}{l}\text { AOA } 47 \% * \\
\text { Antioocyte Aab } 47 \% * \\
\text { AOA or anti-oocyte Aab 69\%* } \\
\text { Anti-LH } 6.7 \% \text { (also AOA positive) } \\
\text { AThA } 18 \% * \\
\text { Antiplacental Aab 22\%* }\end{array}$ & ELISA & CC & Luborsky et al. 1990 [30] \\
\hline POF (45) & AOA $24-60 \% *$ & ELISA & $\mathrm{CC}$ & Wheatcroft et al. 1994 [68] \\
\hline POF (48) & $\begin{array}{l}\text { Anti-3 beta hydroxysteroid dehydrogenase } \\
\text { Aab 21\%* }\end{array}$ & $\begin{array}{l}\text { IB, IF, cDNA } \\
\text { screening }\end{array}$ & CC & Arif et al. 1996 [69] \\
\hline POF (46) & $\begin{array}{l}\text { AOA IgG, IgA or IgM 59\%-IgG 74.1\%, IgA } \\
33.3 \% \text {, IgM } 29.6 \% *\end{array}$ & ELISA & $\mathrm{CC}$ & Fénichel et al. 1997 [29] \\
\hline $\begin{array}{l}\text { (A) POF (14) } \\
\text { (B) IVF poor responders (29) } \\
\text { (C) IVF good responders (14) }\end{array}$ & $\begin{array}{l}\text { FSH blocking IgG: } \\
\text { (A) } 21.4 \% \\
\text { (B) } 6.9 \% \\
\text { (C) } 85 \% *\end{array}$ & $\begin{array}{l}\text { IgG purification, } \\
\text { cell culture } \\
\text { exposure }\end{array}$ & $\mathrm{CC}$ & Reznik et al. 1998 [70] \\
\hline $\begin{array}{l}\text { POF (30) } \\
\text { Unexplained infertility (38) }\end{array}$ & $\begin{array}{l}\text { AOA and AThA 60\%* } \\
\text { ANA and ACA 16\%* } \\
\text { AOA 53\%* } \\
\text { AThA 30\%* }\end{array}$ & EIA & $\mathrm{CC}$ & Luborsky et al. 1999 [32] \\
\hline POS positive for AOA (36) & Anti-FSH (anti-V14D) 94.4\%* & $\begin{array}{c}\text { ELISA, IB, IF, } \\
\text { peptide screening }\end{array}$ & $\mathrm{P}$ & Gobert et al. 2001 [71] \\
\hline POF (15) & $\begin{array}{l}\text { AOA } 66.6 \% * \\
\text { Antizona pellucida Aab } 53.3 \% * \\
\text { TMA } 33.3 \%\end{array}$ & IHC & CC & Kelkar et al. 2005 [31] \\
\hline \multicolumn{5}{|c|}{ IVF patients } \\
\hline $\begin{array}{l}\text { IVF poor responders with male } \\
\text { infertility or TFI (26) }\end{array}$ & $\begin{array}{l}\text { AOA 77\%* } \\
\text { Anti-FSH 92\%* } \\
\text { Anti-LH 65\%* }\end{array}$ & ELISA & CC & Meyer et al. 1990 [72] \\
\hline IVF failure $(80)$ & AOA $12.5 \% *$ & IF & $\mathrm{CC}$ & Geva et al. 1999 [62] \\
\hline IVF failure (17) & $\begin{array}{l}1 \text { out of } 6 \text { common Aab IgG } 82.3 \% * \text { : } \\
\text { ACA } 58.8 \% \\
\text { LA } 47.1 \% \\
\text { AThA } 58.8 \% \\
\text { ANA } 58.8 \% \\
\text { SMA } 11.8 \%\end{array}$ & ELISA, IF, PDCA & $\mathrm{CC}$ & Putowski et al. 2004 [61] \\
\hline $\begin{array}{l}\text { IVF patients (135): } \\
\text { (A) PCOS, endometriosis, } \\
\text { unexplained infertility } \\
\text { (B) TFI or male infertility }\end{array}$ & $\begin{array}{l}\text { (A) and (B) higher titer of anti-FSH IgG, } \\
\text { IgA and IgM* (A) } 1 \text { out of } 7 \text { common Aab } \\
\text { IgG } 49 \% * \text {-ANA } 2 \text { preparations, SMA, PCA, } \\
\text { ACA, B2-GPI or anti-TPO }\end{array}$ & ELISA, IF & CC & Haller et al. 2007 [73] \\
\hline IVF poor responders $(16)$ & $\begin{array}{l}\text { Anti-FSH IgA 37.5\%* } \\
\text { Anti-FSH IgG } 31.3 \% *\end{array}$ & ELISA & $\mathrm{CC}$ & Haller et al. 2008 [74] \\
\hline TFI with IVF failure (156) & AEA IgA* (antialpha enolase) & IB, MS & $\mathrm{CC}$ & Sarapik et al. $2010[43]$ \\
\hline TFI (21) & Antichlamydial HSP60 antibody titer* & ELISA, IB, IF & $\mathrm{CC}$ & Rodgers et al. 2010 [42] \\
\hline \multicolumn{5}{|c|}{ Non-IVF infertility patients } \\
\hline $\begin{array}{l}\text { (A) Unexplained infertility (26) } \\
\text { (B) Unexplained abortion (24) }\end{array}$ & $\begin{array}{l}2 \mathrm{APA}, 5 \text { antihistone or } 4 \text { antipolynucleotide } \\
\operatorname{IgG} \text {, IgA or IgM (A } 88 \% \text { and B } 70.8 \% \text { ) }\end{array}$ & ELISA & $\mathrm{P}$ & Gleicher et al. 1989 [66] \\
\hline $\begin{array}{l}\text { Pregnancy complications (69): } \\
\text { (A) Early pregnancy loss } \\
\text { (B) Foetal death } \\
\text { (C) Preeclampsia }\end{array}$ & $\begin{array}{l}\text { AThA } 37.7 \% * \text { : } \\
\text { (A) } 37.9 \% * \\
\text { (B) } 40.9 \% * \\
\text { (C) } 33.3 \% * \\
\end{array}$ & ELISA, PDCA, RIA & $\mathrm{CC}$ & Mecacci et al. $2000[11]$ \\
\hline
\end{tabular}


TABle 2: Continued.

\begin{tabular}{|c|c|c|c|c|}
\hline Patients $(\mathrm{N})$ & Autoantibodies & Methods & $\begin{array}{l}\text { Study } \\
\text { design }\end{array}$ & Authors (reference no.) \\
\hline $\begin{array}{l}\text { Infertility (108): } \\
\text { Menstrual cycle disturbances } \\
\text { Anovulation } \\
\text { Luteal phase deficiency } \\
\text { Unexplained infertility } \\
\text { PCOS } \\
\text { Endometriosis } \\
\end{array}$ & $\begin{array}{l}1 \text { out of } 9 \text { common Aab IgG } 40.7 \% * \\
\text { ANA } 13.9 \%^{*} \\
\text { SMA } 27.8 \% * \\
\text { TMA } 1.9 \% * \\
\text { PCA } 0.6 \% \\
\text { B2-GPI } 4.4 \% \\
\text { ACA } 5 \%\end{array}$ & ELISA, IF & $\mathrm{CP}$ & Reimand et al. 2001 [25] \\
\hline $\begin{array}{l}\text { Infertility (438): } \\
\text { Endometriosis } \\
\text { TFI } \\
\text { Ovarian dysfunction } \\
\text { Male infertility } \\
\text { Unexplained infertility } \\
\end{array}$ & $\begin{array}{l}\text { Anti-TPO } 14 \% \text { : } \\
18 \% \text { in female infertility* } \\
29 \% \text { in endometriosis* }\end{array}$ & RIA & CC & $\begin{array}{l}\text { Poppe and Velkeniers } 2002 \\
{[60]}\end{array}$ \\
\hline $\begin{array}{l}\text { (A) Infertility (178)—PCOS, } \\
\text { endometriosis } \\
\text { (B) Uncomplicated pregnancy } \\
\text { (75) }\end{array}$ & $\begin{array}{l}\text { (A) higher titer of anti-FSH (anti-V14D) } \\
\text { IgA* } \\
\text { (B) lower titer of anti-FSH (anti-V14D) IgG, } \\
\text { IgM* }\end{array}$ & ELISA & $\mathrm{CC}$ & Haller et al. 2005 [75] \\
\hline \multicolumn{5}{|c|}{ Infertility-related diseases } \\
\hline Endometriosis (13) & $\begin{array}{l}\text { AOA, AEA, anti-theca cell Aab, } \\
\text { anti-granulosa cell Aab titers* }\end{array}$ & IF, PHA & $\mathrm{CC}$ & Mathur et al. 1982 [50] \\
\hline Endometriosis (59) & $\begin{array}{l}\text { ANA } 28.8 \% \text {, LA } 45.5 \% \text { (inversely related to } \\
\text { disease stage) } \\
1 \text { out of } 16 \text { antigens IgG } 64.5 \% \\
1 \text { out of } 16 \text { antigens IgM } 45.2 \%\end{array}$ & IF, PDCA & $\mathrm{P}$ & Gleicher et al. 1987 [21] \\
\hline Endometriosis (60) & $\begin{array}{l}\text { Anti- } \alpha \text { 2HS glycoprotein and antitransferrin } \\
\text { titers* }\end{array}$ & ELISA & CC & Mathur et al. 1999 [49] \\
\hline $\operatorname{PCOS}(34)$ & $\begin{array}{l}\text { AOA IgG, IgA or IgM } 44 \%-\text { IgG } 27 \% \text {, IgA } \\
3 \% \text {, IgM } 27 \% *\end{array}$ & ELISA & CC & Fénichel et al. 1999 [19] \\
\hline
\end{tabular}

${ }^{*}$ Statistically significant compared to the reference $(P<0.05)$, Aab-autoantibodies, ACA-anticardiolipin autoantibodies, AEA-antiendometrial autoantibodies, ANA-antinuclear autoantibodies, AOA-antiovary autoantibodies, APA-antiphospholipid autoantibodies, AThA-anti-thyroid autoantibodies, B2-GPI-antibeta 2-glycoprotein I autoantibodies, EIA-enzyme immunoassay, ELISA-enzyme-linked immunosorbent assay, FSH-follicle stimulating hormone, HSP-heat shock protein, IF-immunofluorescence, IB-immunoblot analysis, IHC-immunohistochemistry, IVF in vitro fertilization, LA-lupus anticoagulant, CC-casecontrol study, CP-cases-population study, LH-luteinizing hormone, MS-mass spectrometry, P-prevalence, PCA-parietal cell autoantibodies, PCOS-polycystic ovary syndrome, PDCA-phospholipid-dependent clotting assay, PHA-passive haemagglutination, POF-premature ovarian failure, RIA-radioimmune assay, SMA-smooth muscle autoantibodies, TFI-tubal factor infertility, TMA-thyroid microsomal autoantibodies, TPO-thyroid peroxidase, V14D-78-93 amino acid immunodominant epitope on FSH.

thyroiditis, may develop secondary to some basic cellular abnormality that directly affects pregnancy outcome $[60,61]$. Repeated IVF failure has been associated with increased prevalence of many autoantibodies, including AOA, APA, ANA, SMA, and antisperm antibodies [61, 62]. Therefore, the failure in differentiation of uterine T-cells into T-regulatory cells, as a key determinant of fertility in women has been suggested to be a case in unexplained infertility [58]. Since the prevalence of AOA in unexplained infertility and POF has been detected similar, the unexplained infertility was suggested to represent an early stage of autoimmune POF [32].

The impact of a particular autoantibody on the pathogenesis of infertility is not uniformly understood. ANA could interfere with early implantation of embryo and SMA could alter the fallopian tube function [23]. It is concluded that APA may be involved in uterine vascular modifications affecting implantation processes [63]. Except AOA in ovulatory dysfunctions and disease-specific autoantibodies described in case of endometriosis $[43,48,49,64]$, autoantibodies detected in infertile patients are usually not specific to infertility or to the gynaecological diseases leading to infertility. Furthermore, the number of detectible autoantibodies, in particular, has been proposed to predict the pregnancy rate of IVF treatment [65]. Therefore, some studies suggest lesser importance of specific autoantibodies and stress the key role of overall activation of the immune system in reduced fecundity $[12,65]$. Consequently, the autoimmune-associated infertility might be a polyclonal event characterized by immunological defects at the T-cell level which, similarly to classical autoimmune diseases, may manifest itself in abnormal antibody production [66].

3.1. Antiovarian Autoantibodies. Although the presence of AOA immunoglobulin G ( $\operatorname{IgG}$ ) has been documented in different groups of infertile patients (Table 2), there are no epidemiological studies of ovarian autoimmunity. Using an estimated prevalence of autoimmune POF, about 1.1 million 
women potentially have ovarian autoimmunity in US, which makes ovarian autoimmunity far more common than Addison's disease, myasthenia gravis, or systemic lupus erythematosus [67].

Some antibodies in the pool of AOA are suggested to associate with a direct action on ovarian tissue, whereas others have no such effects, similar to autoantibodies in other autoimmune diseases [67]. Therefore, it is possible, that several different antigens are involved in ovarian autoimmunity, as both ovarian cellular and zona pellucida/oocyte antibodies have been reported. Antioocyte antibodies were identified already in 1966, and this was also one of the first descriptions of antiovarian autoimmunity [76]. High prevalence of antizona pellucida antibodies have been detected in infertile women, but also in healthy fertile women and even in men [22]. Antibodies to steroid cells (SCA) are more prevalent in POF patients with Addison's disease $(73 \%-87 \%)$, but rare in those patients with other autoimmune disease $(0 \%-8 \%)$ or in $0 \%-10 \%$ of patients with isolated POF [22]. Steroidogenic enzymes such as $17 \alpha$-hydroxylase, desmolase (P450-side chain cleavage), $3 \beta$-hydroxysteroid dehydrogenase, and 21 hydroxylase have been detected as the molecular targets of SCA $[69,77-80]$. The aldehyde dehydrogenase and seleniumbinding protein 1 [81], human heat-shock protein 90-beta [82] and antialpha-enolase [83] has recently been identified as unique antigens in antiovarian autoimmunity associated with POF and infertility. Gonadotrophin receptors have been also investigated as a potential autoantibody targets. While antibodies against $\mathrm{LH}$ receptor were first identified in $30 \%$ of IVF patients and in $50 \%$ of infertile patients with endometriosis $[68,84]$, only few cases of POF patients possessing antibodies to FSH receptor was documented [85]. A later study on FSH receptor blocking ability of these antibodies has allowed questioning the pathophysiological role of anti-FSH receptor antibodies in ovarian failure [70].

Although blocking antibodies are usually considered to interact with receptors, the FSH and $\mathrm{LH}$ activity-inhibiting antibodies could also directly recognize gonadotrophins themselves. The presence of anti-FSH and anti-LH antibodies in poor responder IVF patients has been associated with immunization against exogenous gonadotrophins [72]. Until recently, antigonadotrophin antibodies had been described only in POF patients and that with conflicting results. By using different antibody assays, some authors suggest the importance of only anti-LH antibodies [30], while others evidence the association of POF with anti-FSH antibodies [71]. The latter group presented antibodies against $\beta$-subunit of FSH in nearly all of the studied AOA-positive POF patients and no anti-LH activity was detected in these samples. Moreover, these antibodies recognized epitopes all over the $\beta$-subunit molecule, but a region between amino acids 78 and 93 (V14D) was predominantly recognized in all samples, probably representing the immunodominant epitope [71]. The antibodies detected could readily explain the ovarian failure in POF patients, since this part of the $\beta$-subunit of FSH molecule is directly involved in determining the specificity of receptor binding [86]. The ability of anti-FSH to inhibit the function of FSH hormone has been detected in men [87]. We have looked for the information regarding to the presence of anti-FSH IgG, but also $\operatorname{IgA}$ and $\operatorname{IgM}$, in different etiologic groups of female infertility, in healthy women and during pregnancy. Pregnancy itself is accompanied with a suppression of the development of new ovulating follicles. This ovulatory quiescence is due to an inhibition of the pituitary during pregnancy, as seen in the decreased response of FSH and LH to GnRH administration [88]. In addition, we have been interested in the etiologic factors for overproducing anti-FSH antibodies of all subtypes in infertile women as well as the putative pathological role of these antibodies on folliculogenesis or on effectiveness of infertility treatment.

\section{Follicle Stimulating Hormone}

4.1. Regulation of Gonadal Function by FSH. FSH is one of the two pituitary gonadotrophins involved in the regulation of the gonadal function. In females, FSH targets the receptor expressed only on granulosa cells and induces the maturation of ovarian follicle [89]. FSH can influence the development of preantral follicles via paracrine factors [90]. However, growth of antral follicles becomes critically dependent on FSH support, making a preovulatory follicle capable of ovulation and forming a corpus luteum in response to the mid-cycle surge of LH [91]. The role of FSH and its signalling system is central in the normal reproductive function since mutations in human FSH and its receptor are associated with altered ovarian responses to the hormone, resulting in various degrees of reduced reproductive function [92, 93].

4.2. Coding Genes and Molecular Structure of FSH. FSH is a heterodimer, consisting of an $\alpha$-subunit common to all gonadotrophins (92 amino acids) and a unique $\beta$-subunit (111 amino acids in FSH). Glycosylation of the gonadotrophins is important in circulatory persistence, clearance and in bioactivity [94]. In a solvent environment, two FSH molecules form an asymmetric unit in clasped hands-like fashion [86]. The $\alpha$-subunit carboxy-terminus as well as carbohydrate residues linked to the $\alpha$-subunit have been implicated in receptor binding and activation $[86,94]$. However, there is a cysteine noose, or determinant loop on the $\beta$ subunit of FSH molecule (between amino acids 87 and 94), the residues of which (Asp 88, Asp 90, and Asp 93) play a role in determining the specificity of FSH receptor binding [86].

The receptor-binding and hormone specificity determining $\beta$-subunit of FSH hormone is coded by FSHB gene at the $11 \mathrm{p} 13$ [86]. Haplotype analysis has revealed two most prevalent variants of FSHB gene-HAP1 and HAP13 [95]. These two core haplotypes have been suggested to be associated with female's fecundity [95], but the association with autoimmunity to FSH through gene expression in central tolerance induction towards FSH had not been studied.

\section{Anti-FSH Antibodies Being Primarily Natural Antibodies}

We observed the physiological presence of antibodies directed to FSH in a control group of healthy nonpregnant 
women, significantly lower values of IgG and IgM but not IgA anti-FSH antibodies during uncomplicated pregnancy [75], and increased levels of these antibodies in infertile women [73, 75]. A total of 233 consecutive women undergoing IVF treatment in Estonia constructed the infertility patient group in our studies. We have demonstrated the production of antiFSH IgM antibodies associated with peripheral FSH hormone levels. This association was detected among patients with tubal and male factor infertility [73]. The production of autoantibodies can be enhanced if there is elevated level of autoantigen, as elevated FSH levels and AOA in case of premature menopause [19]. Similarly, autoantibodies and insulin levels in pancreatic $\beta$ cells are correlated [18]. In our study, the level of FSH remained between the reference values for the majority of patients (peripheral level of FSH at the early follicular phase of the menstrual cycle was $8.73 \pm$ 4.69 IU/L). Patients with anti-FSH IgM and FSH correlation had theirs' hormonal level rather lower than in other patients and their infertility was not caused by immune system dysregulation [73]. These results suggest anti-FSH antibodies being primarily the naturally occurring antibodies rather than markers for autoimmunity against FSH hormone. This hypothesis is further supported by the discussion provided by Thomas [96] who concluded that physiological hormone levels remain below a critical threshold for the stimulation of relevant autoimmune reactions [96]. The reason for the correlation between anti-FSH IgM and the level of peripheral hormone is still unknown but could be associated with regulation of FSH bioactivity or with cyclic changes in ovary. The ovulatory process has been compared to a classical local inflammatory reaction and leukocytes have been suggested to participate actively in the cyclic events in the ovary [97-99]. Recently, cumulus and granulosa cells were shown to express cell surface signaling molecules known as pattern recognition receptors acting as sensors of the external environment important for the innate immune system to discriminate self from nonself or altered self antigens [100]. Moreover, a distinct group of mature B-lineage cells, termed B-1 cells are believed to produce IgM natural antibodies, which interact with variety of self determinants and may also cross-react with bacterial antigens [101]. The natural IgMs represent a primitive innate-like layer of adaptive immune system to provide a primary line of defence against systemic infection from viral and bacterial pathogens. There is also evidence that the natural antibodies may contribute to the elimination of autoantigens exposed during tissue damage, for instance, [101].

In addition to the presence in female serum and in ovarian tissue, FSH is also introduced to the genital tract mucosa as a constituent of semen [102]. Female immune system recognizes and reacts to the constituents of semen during insemination, a phenomenon called seminal "priming". Its appropriate activation to induce sperm-prone mucosal tolerance facilitates subsequent pregnancy by sustaining "semiallograft" embryo development $[103,104]$. During the process of partner-specific tolerance, cell-mediated and humoral immune reactions are initiated along with the production of antibodies against semen-specific and shared maternal antigens [103], such as FSH [102]. Therefore, the anti-FSH
IgA antibodies detected in the female circulation could be alloantibodies initiated by semen. According to this hypothesis, levels of anti-FSH IgA would be, depending on how closely tolerance is induced, correlated with IgA antibodies produced against sperm surface antigens. We studied the correlations among patients with regard to their similarities in immunotolerating conditions in the genital tract: (i) tubal factor infertility group-women with tubal factor infertility and normal semen quality observed in their partners, (ii) male factor infertility group-healthy women and impaired sperm quality observed in their partners, and (iii) combined group of patients-women with endometriosis, PCOS or unexplained infertility and normal semen quality observed in their partners [74]. Among all subtypes of antibodies, anti-FSH IgA and anti-sperm IgA were in correlation in combined group of patients [74]. These results suggest that both detected antibodies share the antigenic origin and we propose anti-FSH IgA represent a natural activation of female immune system in inducing the mucosal tolerance to partner antigens. This idea is supported by the previous study, where anti-FSH- $\beta$-chain antibodies were shown to be absent in the sera of children [71].

Somewhat surprisingly, this correlation was only seen in IVF patients with PCOS, endometriosis, and unexplained infertility and not in patients with male factor or tubal factor infertility [74]. The common feature for the former three infertility groups is disturbed regulation of the immune system $[19,24,25,57,58]$. Disruptions of the immune system perturb the female's immune response to semen that is necessary for partner-specific tolerance and thereafter elimination of activated clones to prevent autoimmunity during pregnancy [103]. Semen exerts its "tolerance inducing" effect due to immunomodulating factors, most importantly transforming growth factor $\beta_{1}\left(\operatorname{TGF} \beta_{1}\right)[105,106]$. Seminal levels of TGF $\beta_{1}$ correlate with sperm concentration in ejaculate [105], the most decisive criterion for diagnosing male infertility. However, there is some evidence that male factor infertility is not associated with altered TGF $\beta_{1}$ levels [107]. Although we did not distinguished subgroups of patients with male infertility by sperm parameters, generally their levels of antisperm and anti-FSH antibodies, or correlations between the two, were similar to other patients. Unlike other IVF patients participating in our study, patients with infertility caused by tubal factor do not have disturbances in female immune system regulation or seminal environment. Thus, the diagnosis-restricted correlation of antisperm and anti-FSH IgA cannot be easily explained. However, higher levels of anti-FSH IgA showed an association with the presence of the $H L A-D Q B 1 * 03$ allele [73]. In this context, it is interesting to refer to the published associations between the HLA-DQB1*03 allele, and the presence of the spermimmobilizing antibodies in cervical secretions [108]. Higher production of antisperm antibodies has been detected in patients with increased intestinal permeability in bowel inflammatory disease, as a result of immunization against intestinal microbes, which seems to share common antigenic epitopes with spermatozoa [109]. Consequently, the elevated levels of anti-FSH IgA antibodies in IVF patients could be explained by an upregulation of the normal 
mucosal immune response. Another possible explanation of the increased anti-FSH IgA in IVF patients could be a deficits in producing antibodies that neutralize anti-FSH immunoglobulins, which has been noted in patients who produce antisperm antibodies [110]. These results together suggest that the elevated values of anti-FSH IgA in IVF patients could represent a failure in mucosal tolerance in the genital tract, which could be genetically determined.

The production of anti-FSH IgG and IgM is decreased during uncomplicated pregnancy [75]. This decrease cannot be easily explained by the general view of a shift towards Th2 cytokines favouring humoral immunity during pregnancy [111]. However, in fact, actual elevations of autoantibodies have been detected in patients with pregnancy loss or recurrent abortion rather than in healthy noncomplicated pregnancy $[111,112]$. Therefore, we believe that the development of the FSH-antibodies could reflect some other pregnancyassociated mechanism and that anti-FSH antibodies could be the natural antibodies also in this occasion.

Figure 1(a) summarizes anti-FSH as natural antibodies in healthy women. Humoral immune memory associated with natural antibody-producing B-cells might contribute to the homeostasis of the internal milieu. These cells are also believed to be responsible for autoantigen-mediated clonal selection in the process of initiating autoimmune reactions [101].

\section{Increased Production of Anti-FSH Antibodies Contributes to Female Infertility}

6.1. Higher Values of Anti-FSH in Infertile Women. We observed that anti-FSH antibodies were predominantly produced in infertile patients compared to healthy female blood donors $[73,75]$. As stated earlier, a group of infertile patients from our studies were indicated for IVF, but serum samples were obtained before the administration of exogenous FSH [73]. Thirty-four percent of patients had had at least one previous IVF procedure, but at least three months had passed since the last FSH controlled ovarian hyperstimulation $(\mathrm{COH})$. Furthermore, using stratification by previous IVF procedures, anti-FSH antibody levels were also increased in IVF patients who had never undergone IVF procedures before. The further analysis demonstrated no significant differences in anti-FSH antibody levels between the combined groups of patients with tubal and male factor infertility compared to the women with PCOS, endometriosis, unexplained infertility, and female infertility due to the other causes [73]. These data together suggest that infertility itself, rather than the cause of infertility, could be a predictive factor for the emergence of anti-FSH antibodies, as previously concluded in case of AOA [113]. The intriguing question of what associates the production of anti-FSH antibodies and female infertility stemmed directly from this context.

Female infertility has been shown to be associated with a higher occurrence of autoantibodies [17, 19, 23-25]. Except disease-specific autoantibodies described in case of endometriosis and POF $[22,48,49]$, autoantibodies detected in infertile patients $[17,19,23-25]$ are usually not specific to infertility or to the gynaecological diseases leading to infertility. Thus, a general immune dysbalance and activation of autoimmune processes are expected to be characteristic for female infertility [12]. We have assessed a potential susceptibility of a patient to autoimmunity by the presence of at least 1 out of 7 common IgG type of autoantibodies in relation to the autoimmunity-prone $H L A-D Q B 1$ alleles [73]. Anti-FSH IgM associated with the production of common autoantibodies and this association was not confounded by the presence of $H L A-D Q B 1$ alleles [73]. Our results along the ones from the literature discussed above indicate that the increased production of anti-FSH IgM could be related to a general propensity to autoimmunity in infertile women.

The female infertility has often been studied in the context of IVF. The follicular puncture performed in IVF, in particular, can induce the production of AOA [17]. In concordance with these data, we showed that the level of anti-FSH IgM was higher in the patients who had undergone previous IVF procedures [73]. The association was revealed among IVF patients who were suffering from PCOS, endometriosis, unexplained infertility, and infertility due to the other causes but not among the women with tubal or male factor infertility. These results encourage us to speculate that repeatedly performed ovarian punctures do not enhance antiovarian autoimmunity unless a patient's infertility is caused by the diseases associated with disturbances in immune regulation $[17,19,23-25]$. However, simply based on the association study performed by us, we cannot substantiate whether the antibodies themselves may cause the need for multiple IVF procedures, or alternatively, the use of IVF procedure per se may enhance the production of anti-FSH.

The receptor-binding and hormone specificity determining $\beta$-subunit of FSH hormone is coded by FSHB gene at the $11 \mathrm{p} 13$ [86]. Similarly to insulin gene polymorphisms affecting central tolerance through the level of gene expression in thymus [16], we were looking for an association between the two FSHB core haplotypes [95] and autoimmunity against FSH. As we could not detect such relationship [73], we suggest that either these single nucleotide polymorphisms do not affect gene expression in the thymus during central tolerance induction or that FSHB-associated autoimmunity to FSH depends on HLA$D Q B 1$ allelic variants other than those evaluated in our study [73].

The production of anti-FSH IgA is probably related to different factors than those involved in the production of anti-FSH IgM [73]. Anti-FSH IgA were associated with the presence of the HLA-DQB1*03 allele [74] but not with the cause of infertility, the history of previous IVF attempts or the presence of other autoantibodies [73]. Therefore, it would be tempting to speculate that anti-FSH IgA could not be autoantibodies but alloantibodies triggered by seminal FSH [102] and originating from mucosal response, as discussed above. The reasons for an increased production of this particular IgA isotype of antibodies in IVF patients, however, remain unclear. 


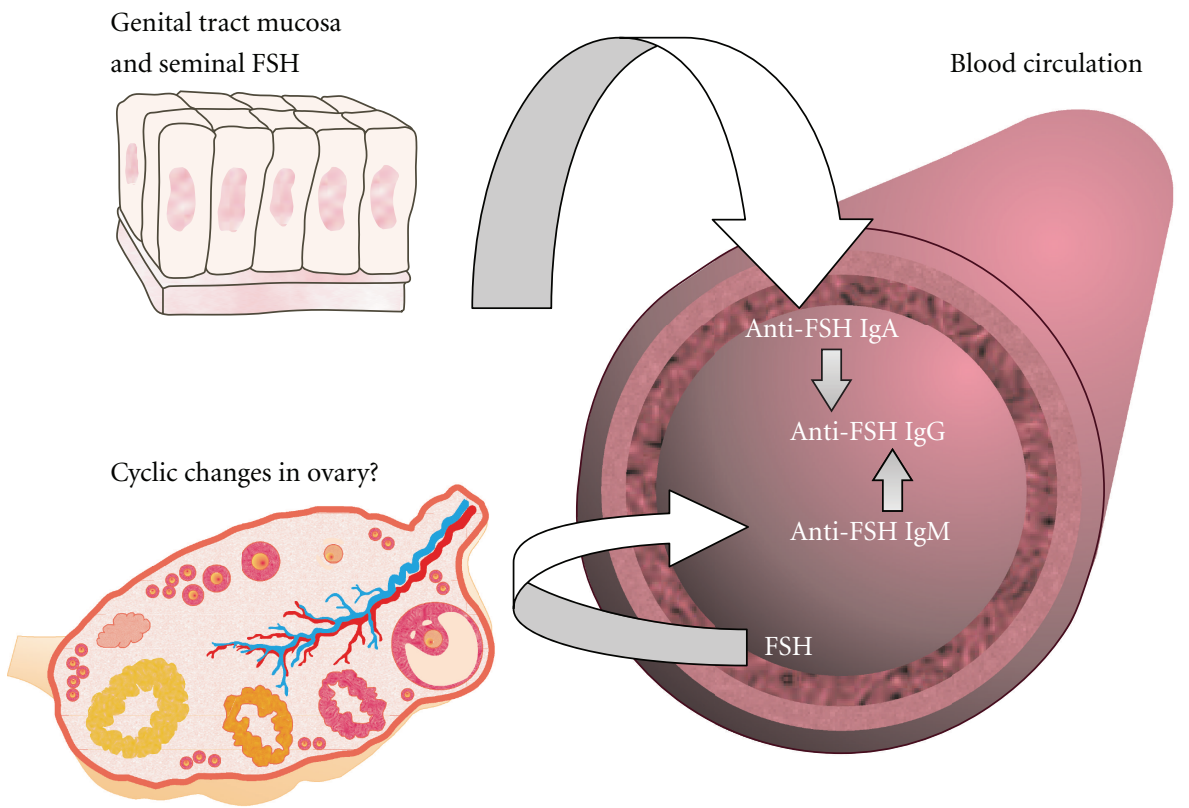

(a)

Failure in mucosal tolerance to seminal FSH

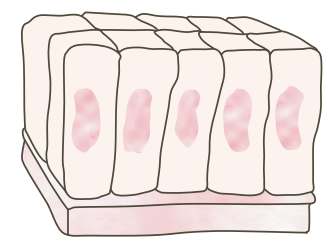

Repeatedly performed

IVF

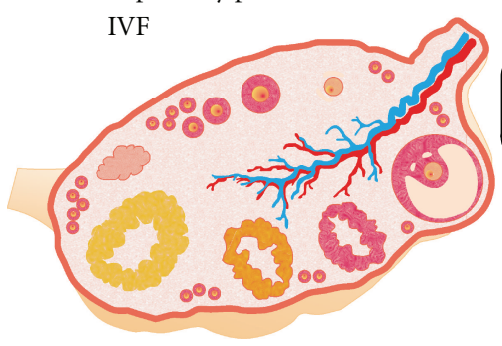

Failure in FSH function folliculogenesis

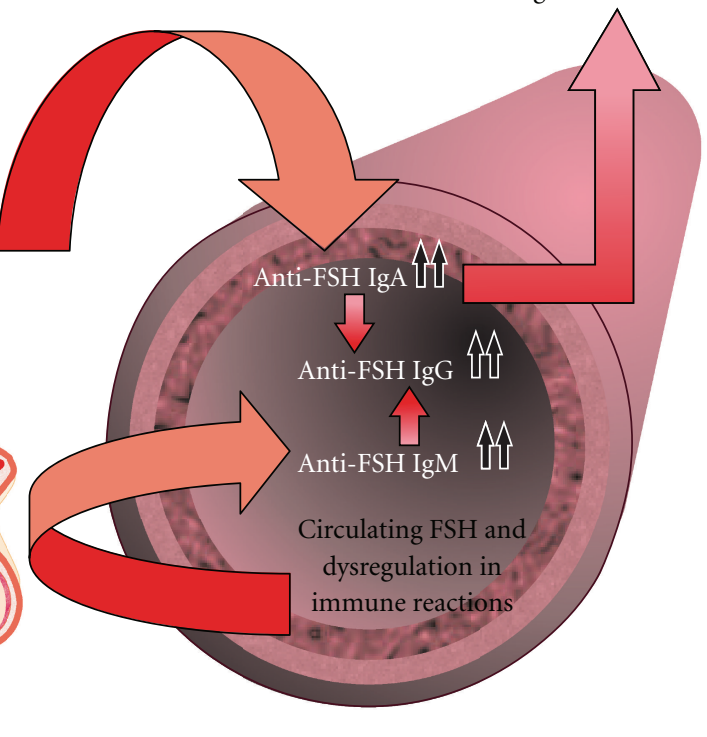

(b)

FIgURE 1: (a) Schematic overview of anti-FSH antibodies in healthy female. Antibodies detected against FSH could be natural antibodies also subjected to pregnancy-associated immune system regulations. Anti-FSH IgA detected in female circulation could be a part of the mucosal response involved in inducing immune tolerance to seminal constituents. Anti-FSH IgM associates with the peripheral level of FSH hormone and possibly contributes along with the mucosal-associated induction of IgA to the production of circulating anti-FSH IgG. (b) Increased production of naturally occurring anti-FSH antibodies in case of female infertility. The production of anti-FSH IgM and IgG antibodies could be related to a general propensity to autoimmunity or to previous IVF treatments. The elevated values of anti-FSH IgA could be explained by a genetically determined failure in mucosal tolerance in the genital tract. Anti-FSH IgG and IgA antibodies, present in sera, accumulate into the preovulatory follicle, where they affect negatively oocyte maturation.

Correlation analysis of anti-FSH antibody values among healthy controls showed that the levels of anti-FSH IgM and IgA correlated both with the values of anti-FSH IgG [73]. There is some indirect evidence that anti-FSH IgG antibodies may, however, further worsen female fecundity by reducing the FSH functionality $[70,72]$. These data lead us to investigate the effect of anti-FSH antibodies on folliculogenesis and developing infertility in women. 
6.2. Effect of Serum Anti-FSH on Folliculogenesis. IVF has become a promising treatment for various causes of infertility. However, the success of attaining pregnancy following IVF depends on the effectiveness of COH. Serum levels of anti-FSH IgG and IgA, but not IgM antibodies at the day of oocyte retrieval, were in linear association with poorer outcome of $\mathrm{COH}$ [114]. The outcome of $\mathrm{COH}$ was defined by the duration of FSH stimulation or the total FSH required attaining an adequate response, the number of follicles punctured or oocytes obtained after $\mathrm{COH}$, the number of mature oocytes or embryos, and the amount of FSH required per all of these parameters. The role of anti-FSH antibodies revealed in our study was quite remarkable. For example, our data suggest that a unit of difference in anti-FSH IgG was associated with a 220.6 IU increase in FSH needed for one zygote, while the mean amount of FSH per zygote was only $443.8 \pm 401.2$ IU. Furthermore, the cutoff value of $>1.0$ for anti-FSH IgA and IgG was calculated to be implicated to poor ovarian response ( $\leq 3$ oocytes) [114]. Series of dilutions of mouse anti-human-FSH monoclonal IgG antibody were used in ELISA test to create a concentration curve and to predict serum anti-FSH IgG antibody concentration. According to the curve, the levels of anti-FSH IgG $>1.0$ was presumed to correspond to the antibody levels higher than $0.5-0.6 \mathrm{mg} / \mathrm{L}$ and could, therefore, represent $0.004 \%$ of expected amount of total $\operatorname{IgG}(8-17 \mathrm{~g} / \mathrm{L})$ in peripheral blood. The same or even slightly lower levels of blocking and stimulating serum TSH-receptor autoantibodies has been demonstrated previously in patients with Graves' disease and in autoimmune hypothyroidism [115]. Since anti-FSH antibodies are often detected in patients with AOA [71, 116] our results may simply reflect an impaired ovarian function due to ovarian autoimmunity. The association between antigonadotrophin [72] or AOA [67] IgG in the sera at oocyte retrieval and poor ovarian response to the FSH stimulation has been shown previously.

In addition to reflecting ovarian autoimmunity, anti-FSH antibodies may impair the function of exogenous or endogenous FSH. For example, anti-FSH could form immune complexes with FSH and induce its clearance, as recently shown for creatine kinase in patients with corresponding antibodies [117]. Also, anti-FSH could interrupt the binding of FSH to its receptor. This hypothesis is supported by our data suggesting anti-FSH antibodies in sera correlated with antibodies directed against the 78-93 amino acid region of the $\beta$-chain of the human FSH $[71,75]$, the domain that determines FSH receptor binding specificity [86]. On the other hand, the study of in vitro FSH-blocking ability of antiFSH IgG in women with good IVF response [70] suggested that anti-FSH antibodies may be nonpathogenic. However, this study did not specify which FSH epitopes were bound by the pool of anti-FSH antibodies.

Although the pathophysiology of anti-FSH in association with poor ovarian response is still unclear, the importance of these antibodies is noteworthy. Woman's age and her ovarian volume and the number of follicles counted at the early follicular phase of her spontaneous menstrual cycle were significant clinical parameters predicting the outcome of $\mathrm{COH}$ [114], as also demonstrated by others [118]. Yet, anti-FSH antibodies could represent an additional importance to the clinical parameters like age, follicle number, or ovarian volume in predicting the outcome of $\mathrm{COH}$. Furthermore, if the influence of anti-FSH on the ovarian response is revealed in the IVF patients (where supraphysiological amounts of FSH were administered to stimulate folliculogenesis), the importance of those antibodies in unstimulated spontaneous folliculogenesis might be substantial.

6.3. Changes in Serum Levels of Anti-FSH during COH in Relation to Follicular Fluid. Serum levels of anti-FSH IgG and IgA, but not IgM antibodies, decreased following $\mathrm{COH}$, conducted with GnRH antagonist protocol [114]. Although interpretation of these results is not straightforward, we believe the decrease in anti-FSH antibody levels could partly be explained by the supraphysiological levels of immunosuppressive progesterone and testosterone $[114,119,120]$ produced in $\mathrm{COH}$. This hypothesis is supported by our previous data suggesting an overall decrease in the number of common IgG autoantibodies during $\mathrm{COH}$ [57]. Additionally, anti-FSH antibodies could form immune complexes with administered recombinant $\mathrm{FSH}$ or with endogenous FSH (produced in pituitary prior to administration of $\mathrm{GnRH}$ antagonists), resulting in the decrease in antibody levels. However, the levels of anti-FSH IgM remain unchanged after $\mathrm{COH}$ [114]. As IgM antibodies also form immune complexes, the reactivation of the immune system towards novel epitopes on the FSH molecule and the production of anti-FSH IgM during $\mathrm{COH}$ might be speculated. As well, immunization against exogenous gonadotrophins has also been previously suggested [72]. This hypothesis is further supported by our findings and that found from the literature that an increase in IgM type of anti-FSH [73] and AOA [17, 32, 73, 121] associated with repeated IVF procedures. However, it was also reported that AOA were initiated by ovarian puncture rather than administered FSH [17]. Additionally, circulating anti-FSH could pass into the follicular fluid during follicle maturation; however, this decrease would hardly be detectable in sera by current laboratory tests.

The charge- and size-selective ovarian blood-follicle barrier is open for IgG to pass into the follicular fluid [122] and the concentration of total IgG and IgA in follicular fluid as well as in blood should be equivalent [123]. We have measured the presence of anti-FSH IgG, IgA and IgM in negligible amounts in follicular fluid [114]. The level of antiFSH IgA also correlated with the level of same antibody in peripheral blood [114]. However, anti-FSH IgG seemed to accumulate into the growing follicle, since the concentration of follicular anti-FSH IgG associated positively with the diameter of a follicle, reflecting the maturity of a follicle [114]. The increase in follicular anti-FSH IgG with the growth of the follicle is not a simple reflection of anti-FSH IgG serum levels, as serum anti-FSH IgG levels significantly decreased during $\mathrm{COH}$ [114]. Logically, follicular anti-FSH IgG levels correlated with the amounts of recombinant FSH used for $\mathrm{COH}$ and FSH levels measured in the follicle [114]. The level of follicular FSH increases while the follicle grows 
$[124,125]$, and expectedly, follicular FSH correlates with the amount of FSH administered exogenously [67, 114]. Thus, anti-FSH IgG could diffuse along with the antigen to the follicular fluid during the $\mathrm{COH}$. Although antiFSH IgA and IgM were detected in the follicle, levels of these antibodies were not associated with follicle diameter [114], which is in agreement with other authors [126]. In addition, anti-FSH IgM levels in the follicle were very low compared to serum antibody levels [114], in concordance with that reported by Clarke and coworkers [123], where total IgM in the follicle represented approximately $10 \%$ of its plasma concentration [123]. Figure 1(b) summarizes our studies on anti-FSH antibodies in cases of female infertility. These results emphasize the need for further research to elucidate the clinical relevance of anti-FSH antibodies in the spontaneous menstrual cycles.

Finally, low-dose prednisolone therapy has improved pregnancy rate in patients with recurrent IVF failure [62, 67,127 ] and in non-IVF patients [128]. Different treatment regimes of oral prednisolone has been suggested, such as $10 \mathrm{mg} / \mathrm{d}$ during one month prior to the $\mathrm{COH}$ [62], $0.5 \mathrm{mg} / \mathrm{kg} / \mathrm{d}$ starting from the beginning of $\mathrm{COH}$ until the end of 1st trimester of pregnancy, and followed by lowering the dose thereafter [127], or $10 \mathrm{mg} / \mathrm{d}$ in the 1 st week, $5 \mathrm{mg} / \mathrm{d}$ in the $2 \mathrm{nd}$ week, $2.5 \mathrm{mg} / \mathrm{d}$ in the $3 \mathrm{rd}$ week, and $2.5 \mathrm{mg} / \mathrm{d} 3$ times a week during the last (4th) week before intrauterine insemination [128]. However, considering the time duration of ovarian folliculogenesis, the treatment should start at least 1-2 months before $\mathrm{COH}$ [67]. Most benefit of immunosuppressive treatment can gain infertile patients who represent antiovarian autoimmunity [129]. Testing serum anti-FSH antibodies could help infertility treatment specialists to identify those patients.

\section{Conclusions}

Female fertility can be affected by diseases or dysfunctions of reproductive tract, neuroendocrine system, and immune system. Reproductive autoimmune failure can be associated with overall activation of immune system or with immune system reactions specifically directed against ovarian antigens. Antiovarian autoantibodies are mostly directed against $\beta$-subunit of follicle stimulating hormone (anti-FSH). AntiFSH could be natural antibodies. Anti-FSH IgA detected in female circulation could be a part of the mucosal response involved in inducing immunotolerance to seminal constituents. Anti-FSH IgM associates with the peripheral level of FSH hormone and contributes along with the mucosalassociated induction of IgA to the production of circulating anti-FSH IgG. Additionally, higher production of anti-FSH antibodies could contribute to female infertility. The induced production of anti-FSH IgM antibodies could be related to a general propensity to autoimmunity or to previous IVF treatments. The elevated values of anti-FSH IgA could indicate genetically determined failure in mucosal tolerance in the genital tract. Serum IgG and IgA anti-FSH antibodies, measured at the day of oocyte retrieval, predict the outcome of ovarian stimulation, additionally to that observed with age and other clinical parameters characterizing the ovarian reserve. A population of anti-FSH antibodies which are produced against 78-93 epitope on the $\beta$-chain might modulate the recognition and binding of FSH to its receptor and might, therefore, have a pathological influence on ovarian function. We have also demonstrated that anti-FSH IgG, IgA, and traces of IgM antibodies were detectable in the follicular fluid and that anti-FSH IgG antibodies accumulated into the preovulatory follicle. Immunosuppressive treatment could improve the pregnancy rate in anti-FSH seropositive infertile patients.

\section{Acknowledgments}

This work was supported by the Estonian Science Foundation (Grants nos. ETF4631, ETF6514, ETF5796, and ETF6498); the Estonian Ministry of Education and Research (core Grants nos. SF0182586s03 and SF0180044s09); Enterprise Estonia (Grant no. EU30200); Estonia-France Parrot grant; scholarships of Centre of Molecular and Clinical Medicine, University of Tartu; scholarship of Andreas and Dr. Elmerice Traks and a grant from UHP-BQRI in Faculté de Médecine et CHU de Nancy, Université Henri Poincaré, Nancy, France.

\section{References}

[1] D. T. Baird, G. Benagiano, J. Cohen et al., "Physiopathological determinants of human infertility," Human Reproduction Update, vol. 8, no. 5, pp. 435-447, 2002.

[2] "Infertility revisited: the state of the art today and tomorrow. The ESHRE Capri Workshop. European Society for Human Reproduction and Embryology," Human Reproduction, vol. 11, no. 8, pp. 1779-1807, 1996.

[3] A. Templeton, J. K. Morris, and W. Parslow, "Factors that affect outcome of in-vitro fertilisation treatment," Lancet, vol. 348, no. 9039, pp. 1402-1406, 1996.

[4] A. Templeton and J. K. Morris, "Reducing the risk of multiple births by transfer of two embryos after in vitro fertilization," The New England Journal of Medicine, vol. 339, no. 9, pp. 573577, 1998.

[5] P. C. Steptoe and R. G. Edwards, "Birth after the reimplantation of a human embryo," Lancet, vol. 2, no. 8085, p. 366, 1978.

[6] K. G. Nygren, A. N. Andersen, and L. Gianaroli, "Assisted reproductive technology in Europe, 1999. Results generated from European registers by ESHRE," Human Reproduction, vol. 17, no. 12, pp. 3260-3274, 2002.

[7] I. T. Chilcott, R. Margara, H. Cohen et al., "Pregnancy outcome is not affected by antiphospholipid antibody status in women referred for in vitro fertilization," Fertility and Sterility, vol. 73, no. 3, pp. 526-530, 2000.

[8] E. Geva, Y. Yaron, J. B. Lessing et al., "Circulating autoimmune antibodies may be responsible for implantation failure in in vitro fertilization," Fertility and Sterility, vol. 62, no. 4, pp. 802-806, 1994.

[9] N. Gleicher, "The role of humoral immunity in endometriosis," Acta Obstetricia et Gynecologica Scandinavica, Supplement, vol. 73, no. 159, pp. 15-17, 1994.

[10] M. D. Hornstein, O. K. Davis, J. B. Massey, R. J. Paulson, and J. A. Collins, "Antiphospholipid antibodies and in vitro 
fertilization success: a meta-analysis," Fertility and Sterility, vol. 73, no. 2, pp. 330-333, 2000.

[11] F. Mecacci, E. Parretti, R. Cioni et al., "Thyroid autoimmunity and its association with non-organ-specific antibodies and subclinical alterations of thyroid function in women with a history of pregnancy loss or preeclampsia," Journal of Reproductive Immunology, vol. 46, no. 1, pp. 39-50, 2000.

[12] N. Gleicher, "Antiphospholipid antibodies (aPL) affect in vitro fertilization (IVF) outcome," American Journal of Reproductive Immunology, vol. 46, no. 5, pp. 330-331, 2001.

[13] G. T. Nepom and W. W. Kwok, "Molecular basis for HLA-DQ associations with IDDM," Diabetes, vol. 47, no. 8, pp. 11771184, 1998.

[14] P. A. Muraro and D. C. Douek, "Renewing the T cell repertoire to arrest autoimmune aggression," Trends in Immunology, vol. 27, no. 2, pp. 61-67, 2006.

[15] J. M. Jasinski and G. S. Eisenbarth, "Insulin as a primary autoantigen for type 1A diabetes," Clinical \& Developmental Immunology, vol. 12, no. 3, pp. 181-186, 2005.

[16] P. Vafiadis, H. Ounissi-Benkalha, M. Palumbo et al., "Class III alleles of the variable number of tandem repeat insulin polymorphism associated with silencing of thymic insulin predispose to type 1 diabetes," The Journal of Clinical Endocrinology and Metabolism, vol. 86, no. 8, pp. 3705-3710, 2001.

[17] B. Gobert, P. Barbarino-Monnier, F. Guillet-May, M. C. Bene, and G. C. Faure, "Anti-ovary antibodies after attempts at human in vitro fertilization induced by follicular puncture rather than hormonal stimulation," Journal of Reproduction \& Fertility, vol. 96, no. 1, pp. 213-218, 1992.

[18] C. A. Byersdorfer, G. G. Schweitzer, and E. R. Unanue, "Diabetes is predicted by the $\beta$ cell level of autoantigen," Journal of Immunology, vol. 175, no. 7, pp. 4347-4354, 2005.

[19] P. Fénichel, B. Gobert, Y. Carré, P. Barbarino-Monnier, and S. Hiéronimus, "Polycystic ovary syndrome in autoimmune disease," Lancet, vol. 353, no. 9171, p. 2210, 1999.

[20] V. K. Tuohy and R. P. Kinkel, "Epitope spreading: a mechanism for progression of autoimmune disease," Archivum Immunologiae et Therapiae Experimentalis, vol. 48, no. 5, pp. 347-351, 2000.

[21] N. Gleicher, A. El-Roeiy, E. Confino, and J. Friberg, "Is endometriosis an autoimmune disease?" Obstetrics \& Gynecology, vol. 70, no. 1, pp. 115-122, 1987.

[22] T. Forges, P. Monnier-Barbarino, G. C. Faure, and M. C. Béné, "Autoimmunity and antigenic targets in ovarian pathology," Human Reproduction Update, vol. 10, no. 2, pp. 163-175, 2004.

[23] E. Geva, A. Amit, L. Lerner-Geva, and J. B. Lessing, "Autoimmunity and reproduction," Fertility and Sterility, vol. 67, no. 4, pp. 599-611, 1997.

[24] G. Matarese, G. de Placido, Y. Nikas, and C. Alviggi, "Pathogenesis of endometriosis: natural immunity dysfunction or autoimmune disease?" Trends in Molecular Medicine, vol. 9, no. 5, pp. 223-228, 2003.

[25] K. Reimand, I. Talja, K. Metsküla, Ü. Kadastik, K. Matt, and R. Uibo, "Autoantibody studies of female patients with reproductive failure," Journal of Reproductive Immunology, vol. 51, no. 2, pp. 167-176, 2001.

[26] A. S. Bats, P. M. Barbarino, M. C. Bene, G. C. Faure, and T. Forges, "Local lymphocytic and epithelial activation in a case of autoimmune oophoritis," Fertility and Sterility, vol. 90, no. 3, pp. 849.e5-849.e8, 2008.

[27] G. Yan, D. Schoenfeld, C. Penney, K. Hurxthal, A. E. Taylor, and D. Faustman, "Identification of premature ovarian failure patients with underlying autoimmunity," Journal of
Women's Health and Gender-Based Medicine, vol. 9, no. 3, pp. 275-287, 2000.

[28] P. G. Crosignani and B. L. Rubin, "Optimal use of infertility diagnostic tests and treatments. The ESHRE Capri Workshop Group," Human Reproduction, vol. 15, no. 3, pp. 723-732, 2000.

[29] P. Fénichel, C. Sosset, P. Barbarino-Monnier et al., "Prevalence, specificity and significance of ovarian antibodies during spontaneous premature ovarian failure," Human Reproduction, vol. 12, no. 12, pp. 2623-2628, 1997.

[30] J. L. Luborsky, I. Visintin, S. Boyers, T. Asari, B. Caldwell, and A. DeCherney, "Ovarian antibodies detected by immobilized antigen immunoassay in patients with premature ovarian failure," The Journal of Clinical Endocrinology and Metabolism, vol. 70, no. 1, pp. 69-75, 1990.

[31] R. L. Kelkar, P. K. Meherji, S. S. Kadam, S. K. Gupta, and T. D. Nandedkar, "Circulating auto-antibodies against the zona pellucida and thyroid microsomal antigen in women with premature ovarian failure," Journal of Reproductive Immunology, vol. 66, no. 1, pp. 53-67, 2005.

[32] J. Luborsky, B. Llanes, S. Davies, Z. Binor, E. Radwanska, and R. Pong, "Ovarian autoimmunity: greater frequency of autoantibodies in premature menopause and unexplained infertility than in the general population," Clinical Immunology, vol. 90, no. 3, pp. 368-374, 1999.

[33] A. Dunaif, "Hyperandrogenic anovulation (PCOS): a unique disorder of insulin action associated with an increased risk of non-insulin-dependent diabetes mellitus," The American Journal of Medicine, vol. 98, no. 1A, pp. 33S-39S, 1995.

[34] E. S. Knochenhauer, T. J. Key, M. Kahsar-Miller, W. Waggoner, L. R. Boots, and R. Azziz, "Prevalence of the polycystic ovary syndrome in unselected black and white women of the Southeastern United States: a prospective study," The Journal of Clinical Endocrinology and Metabolism, vol. 83, no. 9, pp. 3078-3082, 1998.

[35] "Revised 2003 consensus on diagnostic criteria and longterm health risks related to polycystic ovary syndrome (PCOS)," Human Reproduction, vol. 19, no. 1, pp. 41-47, 2004.

[36] A. Dunaif, "Insulin resistance and the polycystic ovary syndrome: mechanism and implications for pathogenesis," Endocrine Reviews, vol. 18, no. 6, pp. 774-800, 1997.

[37] L. Harborne, R. Fleming, H. Lyall, J. Norman, and N. Sattar, "Descriptive review of the evidence for the use of metformin in polycystic ovary syndrome," Lancet, vol. 361, no. 9372, pp. 1894-1901, 2003.

[38] J. A. Land and J. L. Evers, "Chlamydia infection and subfertility," Best Practice \& Research: Clinical Obstetrics \& Gynaecology, vol. 16, no. 6, pp. 901-912, 2002.

[39] A. Uusküla, T. Plank, A. Lassus, and J. S. Bingham, "Sexually transmitted infections in Estonia—syndromic management of urethritis in a European country?" International Journal of STD \& AIDS, vol. 12, no. 8, pp. 493-498, 2001.

[40] A. Uusküla, H. Silm, and T. Vessin, "Sexually transmitted diseases in Estonia: past and present," International Journal of STD \& AIDS, vol. 8, no. 7, pp. 446-450, 1997.

[41] H. C. Wiesenfeld, S. L. Hillier, M. A. Krohn et al., "Lower genital tract infection and endometritis: insight into subclinical pelvic inflammatory disease," Obstetrics and Gynecology, vol. 100, no. 3, pp. 456-463, 2002.

[42] A. K. Rodgers, J. Wang, Y. Zhang et al., "Association of tubal factor infertility with elevated antibodies to Chlamydia 
trachomatis caseinolytic protease P," American Journal of Obstetrics and Gynecology, vol. 203, no. 5, pp. 494.e7494.e14, 2010.

[43] A. Sarapik, K. Haller-Kikkatalo, M. Utt, K. Teesalu, A. Salumets, and R. Uibo, "Serum anti-endometrial antibodies in infertile women-potential risk factor for implantation failure," American Journal of Reproductive Immunology, vol. 63, no. 5, pp. 349-357, 2010.

[44] M. B. Goldman and D. W. Cramer, "The epidemiology of endometriosis," Progress in Clinical and Biological Research, vol. 323, pp. 15-31, 1990.

[45] J. M. Wheeler, "Epidemiology of endometriosis-associated infertility," The Journal of Reproductive Medicine, vol. 34, no. 1, pp. 41-46, 1989.

[46] S. Vassiliadis, K. Relakis, A. Papageorgiou, and I. Athanassakis, "Endometriosis and infertility: a multi-cytokine imbalance versus ovulation, fertilization and early embryo development," Clinical \& Developmental Immunology, vol. 12, no. 2, pp. 125-129, 2005.

[47] D. I. Lebovic, M. D. Mueller, and R. N. Taylor, "Immunobiology of endometriosis," Fertility and Sterility, vol. 75, no. 1, pp. 1-10, 2001.

[48] G. A. Lang and G. R. Yeaman, "Autoantibodies in endometriosis sera recognize a Thomsen-Friedenreich-like carbohydrate antigen," Journal of Autoimmunity, vol. 16, no. 2, pp. 151-161, 2001.

[49] S. P. Mathur, J. H. Lee, H. Jiang, P. Arnaud, and P. F. Rust, "Levels of transferrin and alpha 2-HS glycoprotein in women with and without endometriosis," Autoimmunity, vol. 29, no. 2, pp. 121-127, 1999.

[50] S. Mathur, M. R. Peress, and H. O. Williamson, "Autoimmunity to endometrium and ovary in endometriosis," Clinical and Experimental Immunology, vol. 50, no. 2, pp. 259-266, 1982.

[51] Z. Ulcová-Gallová, V. Bouše, L. Švábek, J. Turek, and Z. Rokyta, "Endometriosis in reproductive immunology," American Journal of Reproductive Immunology, vol. 47, no. 5, pp. 269-274, 2002.

[52] E. R. Barnea, T. R. Holford, and D. R. McInnes, "Long-term prognosis of infertile couples with normal basic investigations: a life-table analysis," Obstetrics and Gynecology, vol. 66, no. 1, pp. 24-26, 1985.

[53] A. A. Templeton and G. C. Penney, "The incidence, characteristics, and prognosis of patients whose infertility is unexplained," Fertility and Sterility, vol. 37, no. 2, pp. 175$182,1982$.

[54] S. Altmäe, J. A. Martínez-Conejero, A. Salumets et al., "Endometrial gene expression analysis at the time of embryo implantation in women with unexplained infertility," Molecular Human Reproduction, vol. 16, no. 3, pp. 178-187, 2010.

[55] S. Altmäe, A. Salumets, K. Bjuresten et al., "Tissue factor and tissue factor pathway inhibitors TFPI and TFPI2 in human secretory endometrium-possible link to female infertility," Reproductive Sciences, vol. 18, no. 7, pp. 666-678, 2011.

[56] S. Altmäe, A. Stavreus-Evers, J. R. Ruiz et al., "Variations in folate pathway genes are associated with unexplained female infertility," Fertility and Sterility, vol. 94, no. 1, pp. 130-137, 2010.

[57] K. Haller, A. Sarapik, I. Talja, A. Salumets, and R. Uibo, "Controlled ovarian hyperstimulation changes the prevalence of serum autoantibodies in in vitro fertilization patients," American Journal of Reproductive Immunology, vol. 56, no. 56, pp. 364-370, 2006.
[58] M. J. Jasper, K. P. Tremellen, and S. A. Robertson, "Primary unexplained infertility is associated with reduced expression of the T-regulatory cell transcription factor Foxp3 in endometrial tissue," Molecular Human Reproduction, vol. 12, no. 5, pp. 301-308, 2006.

[59] P. Monteleone, D. Parrini, P. Faviana et al., "Female infertility related to thyroid autoimmunity: the ovarian follicle hypothesis," American Journal of Reproductive Immunology, vol. 66, no. 2, pp. 108-114, 2011.

[60] K. Poppe and B. Velkeniers, “Thyroid and infertility," Verhandelingen-Koninklijke Academie voor Geneeskunde van Belgie, vol. 64, no. 6, pp. 389-399, 2002.

[61] L. Putowski, D. Darmochwal-Kolarz, J. Rolinski, J. Oleszczuk, and J. Jakowicki, "The immunological profile of infertile women after repeated IVF failure (preliminary study)," European Journal of Obstetrics Gynecology and Reproductive Biology, vol. 112, no. 2, pp. 192-196, 2004.

[62] E. Geva, G. Fait, L. Lerner-Geva et al., "The possible role of antiovary antibodies in repeated in vitro fertilization failures," American Journal of Reproductive Immunology, vol. 42, no. 5, pp. 292-296, 1999.

[63] C. Battaglia, L. Sgarbi, M. Salvatori, N. Maxia, A. Gallinelli, and A. Volpe, "Increased anticardiolipin antibodies are positively related to the uterine artery pulsatility index in unexplained infertility," Human Reproduction, vol. 13, no. 12, pp. 3487-3491, 1998.

[64] S. P. Mathur, "Autoimmunity in endometriosis: relevance to infertility," American Journal of Reproductive Immunology, vol. 44, no. 2, pp. 89-95, 2000.

[65] W. P. Dmowski, N. Rana, J. Michalowska, J. Friberg, C. Papierniak, and A. El-Roeiy, "The effect of endometriosis, its stage and activity, and of autoantibodies on in vitro fertilization and embryo transfer success rates," Fertility and Sterility, vol. 63, no. 3, pp. 555-562, 1995.

[66] N. Gleicher, A. El-Roeiy, E. Confino, and J. Friberg, "Reproductive failure because of autoantibodies: unexplained infertility and pregnancy wastage," American Journal of Obstetrics and Gynecology, vol. 160, no. 6, pp. 1376-1380, 1989.

[67] J. Luborsky, "Ovarian autoimmune disease and ovarian autoantibodies," Journal of Women's Health and Gender-Based Medicine, vol. 11, no. 7, pp. 585-599, 2002.

[68] N. J. Wheatcroft, A. A. Toogood, T. C. Li, I. D. Cooke, and A. P. Weetman, "Detection of antibodies to ovarian antigens in women with premature ovarian failure," Clinical and Experimental Immunology, vol. 96, no. 1, pp. 122-128, 1994.

[69] S. Arif, S. Vallian, F. Farzaneh et al., "Identification of $3 \beta$ hydroxysteroid dehydrogenase as a novel target of steroid cell autoantibodies: association of autoantibodies with endocrine autoimmune disease," The Journal of Clinical Endocrinology and Metabolism, vol. 81, no. 12, pp. 4439-4445, 1996.

[70] Y. Reznik, A. Benhaïm, R. Morello, M. Herlicoviez, J. J. Ballet, and J. Mahoudeau, "High frequency of IgG antagonizing follicle-stimulating hormone- stimulated steroidogenesis in infertile women with a good response to exogenous gonadotropins," Fertility and Sterility, vol. 69, no. 1, pp. 46$52,1998$.

[71] B. Gobert, C. Jolivet-Reynaud, P. Dalbon et al., "An immunoreactive peptide of the FSH involved in autoimmune infertility," Biochemical and Biophysical Research Communications, vol. 289, no. 4, pp. 819-824, 2001.

[72] W. R. Meyer, G. Lavy, A. H. DeCherney, I. Visintin, K. Economy, and J. L. Luborsky, "Evidence of gonadal and 
gonadotropin antibodies in women with a suboptimal ovarian response to exogenous gonadotropin," Obstetrics and Gynecology, vol. 75, no. 5, pp. 795-799, 1990.

[73] K. Haller, A. Salumets, M. Grigorova et al., "Putative predictors of antibodies against follicle-stimulating hormone in female infertility: a study based on in vitro fertilization patients," American Journal of Reproductive Immunology, vol. 57, no. 3, pp. 193-200, 2007.

[74] K. Haller, A. Sikut, H. Karro, R. Uibo, and A. Salumets, "Circulating anti-follicle-stimulating hormone immunoglobulin A in women: a sperm-prone reaction of mucosal tolerance?" Fertility and Sterility, vol. 90, no. 4, pp. 1253-1255, 2008.

[75] K. Haller, C. Mathieu, K. Rull, K. Matt, M. C. Béné, and R. Uibo, "IgG, IgA and IgM antibodies against FSH: serological markers of pathogenic autoimmunity or of normal immunoregulation?" American Journal of Reproductive Immunology, vol. 54, no. 5, pp. 262-269, 2005.

[76] M. B. Vallotton and A. P. Forbes, "Antibodies to cytoplasm of ova," Lancet, vol. 2, no. 7457, pp. 264-265, 1966.

[77] S. Chen, J. Sawicka, C. Betterle et al., "Autoantibodies to steroidogenic enzymes in autoimmune polyglandular syndrome, Addison's disease, and premature ovarian failure," The Journal of Clinical Endocrinology and Metabolism, vol. 81, no. 5, pp. 1871-1876, 1996.

[78] P. Peterson, R. Uibo, J. Peränen, and K. Krohn, "Immunoprecipitation of steroidogenic enzyme autoantigens with autoimmune polyglandular syndrome type I (APS I) sera; further evidence for independent humoral immunity to P450c17 and P450c21," Clinical and Experimental Immunology, vol. 107, no. 2, pp. 335-340, 1997.

[79] K. Reimand, P. Peterson, H. Hyöty et al., " $3 \beta$-hydroxysteroid dehydrogenase autoantibodies are rare in premature ovarian failure," Journal of Clinical Endocrinology and Metabolism, vol. 85, no. 6, pp. 2324-2326, 2000.

[80] R. Uibo, E. Aavik, P. Peterson et al., "Autoantibodies to cytochrome P450 enzymes P450scc, P450c17, and P450c21 in autoimmune polyglandular disease types I and II and in isolated Addison's disease," Journal of Clinical Endocrinology and Metabolism, vol. 78, no. 2, pp. 323-328, 1994.

[81] S. L. Edassery, S. V. Shatavi, J. P. Kunkel et al., "Autoantigens in ovarian autoimmunity associated with unexplained infertility and premature ovarian failure," Fertility and Sterility, vol. 94, no. 7, pp. 2636-2641, 2010.

[82] E. S. Pires and V. V. Khole, "A block in the road to fertility: autoantibodies to heat-shock protein $90-\beta$ in human ovarian autoimmunity," Fertility and Sterility, vol. 92, no. 4, pp. 13951409, 2009.

[83] V. Sundblad, L. Bussmann, V. A. Chiauzzi, V. Pancholi, and E. H. Charreau, " $\alpha$-enolase: a novel autoantigen in patients with premature ovarian failure," Clinical Endocrinology, vol. 65, no. 6, pp. 745-751, 2006.

[84] H. Moncayo, R. Moncayo, R. Benz, A. Wolf, and C. Lauritzen, "Ovarian failure and autoimmunity. Detection of autoantibodies directed against both the unoccupied luteinizing hormone/human chorionic gonadotropin receptor and the hormone-receptor complex of ovine corpus luteum," The Journal of Clinical Investigation, vol. 84, no. 6, pp. 1857-1865, 1989.

[85] V. Chiauzzi, S. Cigorraga, M. E. Escobar, M. A. Rivarola, and E. H. Charreau, "Inhibition of follicle-stimulating hormone receptor binding by circulating immunoglobulins," The Journal of Clinical Endocrinology and Metabolism, vol. 54, no. 6, pp. 1221-1228, 1982.
[86] K. M. Fox, J. A. Dias, and P. van Roey, "Three-dimensional structure of human follicle-stimulating hormone," Molecular Endocrinology, vol. 15, no. 3, pp. 378-389, 2001.

[87] W. E. Westhoff, J. W. Slootstra, W. C. Puijk et al., "Detection of epitopes on follicle-stimulating hormone and FSHantiserum-induced suppression of bioactivity of folliclestimulating hormone and luteinizing hormone," Journal of Reproductive Immunology, vol. 30, no. 2-3, pp. 133-149, 1996.

[88] L. M. Rubinstein, A. F. Parlow, C. Derzko, and J. Hershman, "Pituitary gonadotropin response to LHRH in human pregnancy," Obstetrics \& Gynecology, vol. 52, no. 2, pp. 172-175, 1978.

[89] A. P. N. Themmen and I. T. Huhtaniemi, "Mutations of gonadotropins and gonadotropin receptors: elucidating the physiology and pathophysiology of pituitary-gonadal function," Endocrine Reviews, vol. 21, no. 5, pp. 551-583, 2000.

[90] F. H. Thomas and B. C. Vanderhyden, "Oocyte-granulosa cell interactions during mouse follicular development: regulation of kit ligand expression and its role in oocyte growth," Reproductive Biology and Endocrinology, vol. 4, article 19, 2006.

[91] P. G. Knight and C. Glister, "TGF- $\beta$ superfamily members and ovarian follicle development," Reproduction, vol. 132, no. 2, pp. 191-206, 2006.

[92] I. T. Huhtaniemi and K. Aittomäki, "Mutations of folliclestimulating hormone and its receptor: effects on gonadal function," European Journal of Endocrinology/European Federation of Endocrine Societies, vol. 138, no. 5, pp. 473-481, 1998.

[93] J. Levallet, P. Pakarinen, and I. T. Huhtaniemi, "Folliclestimulating hormone ligand and receptor mutations, and gonadal dysfunction," Archives of Medical Research, vol. 30, no. 6, pp. 486-494, 1999.

[94] A. Ulloa-Aguirre and C. Timossi, "Structure-function relationship of follicle-stimulating hormone and its receptor," Human Reproduction Update, vol. 4, no. 3, pp. 260-283, 1998.

[95] M. Grigorova, K. Rull, and M. Laan, "Haplotype structure of FSHB, the beta-subunit gene for fertility-associated folliclestimulating hormone: possible influence of balancing selection," Annals of Human Genetics, vol. 71, no. 1, pp. 18-28, 2007.

[96] J. W. Thomas, "Antigen-specific responses in autoimmunity and tolerance," Immunologic Research, vol. 23, no. 2-3, pp. 235-244, 2001.

[97] L. L. Espey, "Current status of the hypothesis that mammalian ovulation is comparable to an inflammatory reaction," Biology of Reproduction, vol. 50, no. 2, pp. 233-238, 1994.

[98] S. Kõks, A. Velthut, A. Sarapik, S. Altmäe et al., "The differential transcriptome and ontology profiles of floating and cumulus granulosa cells in stimulated human antral follicles," Molecular Human Reproduction, vol. 16, no. 4, pp. 229-240, 2009.

[99] J. S. Richards, D. L. Russell, S. Ochsner, and L. L. Espey, "Ovulation: new dimensions and new regulators of the inflammatory-like response," Annual Review of Physiology, vol. 64, pp. 69-92, 2002.

[100] M. Shimada, I. Hernandez-Gonzalez, I. Gonzalez-Robanya, and J. S. Richards, "Induced expression of pattern recognition receptors in cumulus oocyte complexes: novel evidence for innate immune-like functions during ovulation," Molecular Endocrinology, vol. 20, no. 12, pp. 3228-3239, 2006. 
[101] C. J. Binder and G. J. Silverman, "Natural antibodies and the autoimmunity of atherosclerosis," Springer Seminars in Immunopathology, vol. 26, no. 4, pp. 385-404, 2005.

[102] R. Luboshitzky, M. Kaplan-Zverling, Z. Shen-Orr, R. Nave, and P. Herer, "Seminal plasma androgen/oestrogen balance in infertile men," International Journal of Andrology, vol. 25, no. 6, pp. 345-351, 2002.

[103] U. C. Hegde, S. Ranpura, S. D’Souza, and V. P. Raghavan, "Immunoregulatory pathways in pregnancy," Indian Journal of Biochemistry and Biophysics, vol. 38, no. 4, pp. 207-219, 2001.

[104] S. A. Robertson, J. J. Bromfield, and K. P. Tremellen, "Seminal "priming" for protection from pre-eclampsia-a unifying hypothesis," Journal of Reproductive Immunology, vol. 59, no. 2, pp. 253-265, 2003.

[105] R. Ochsenkühn, A. E. O’Connor, J. J. Hirst, H. W. Gordon Baker, D. M. de Kretser, and M. P. Hedger, "The relationship between immunosuppressive activity and immunoregulatory cytokines in seminal plasma: influence of sperm autoimmunity and seminal leukocytes," Journal of Reproductive Immunology, vol. 71, no. 1, pp. 57-74, 2006.

[106] S. A. Robertson, W. V. Ingman, S. O'Leary, D. J. Sharkey, and K. P. Tremellen, "Transforming growth factor $\beta-\mathrm{a}$ mediator of immune deviation in seminal plasma," Journal of Reproductive Immunology, vol. 57, no. 1-2, pp. 109-128, 2002 .

[107] B. Loras, F. Vételé, A. El Malki, J. Rollet, J. C. Soufir, and M. Benahmed, "Seminal transforming growth factor- $\beta$ in normal and infertile men," Human Reproduction, vol. 14, no. 6, pp. 1534-1539, 1999.

[108] Y. Tsuji, M. Mitsuo, R. Yasunami, K. Sakata, H. Shibahara, and K. Koyama, "HLA-DR and HLA-DQ gene typing of infertile women possessing sperm-immobilizing antibody," Journal of Reproductive Immunology, vol. 46, no. 1, pp. 31$38,2000$.

[109] D. Dimitrova, S. Kalaydjiev, A. Mendizova, E. Piryova, and L. Nakov, "Circulating antibodies to human spermatozoa in patients with ulcerative colitis," Fertility and Sterility, vol. 84, no. 5, pp. 1533-1535, 2005.

[110] R. K. Naz, K. Ahmad, and A. C. Menge, "Antiidiotypic antibodies to sperm in sera of fertile women that neutralize antisperm antibodies," The Journal of Clinical Investigation, vol. 92, no. 5, pp. 2331-2338, 1993.

[111] N. Gleicher, "Autoantibodies in normal and abnormal pregnancy," American Journal of Reproductive Immunology, vol. 28, no. 3-4, pp. 269-273, 1992.

[112] G. E. Eroglu and E. Scopelitis, "Antinuclear and antiphospholipid antibodies in healthy women with recurrent spontaneous abortion," American Journal of Reproductive Immunology, vol. 31, no. 1, pp. 1-6, 1994.

[113] E. Geva, N. Vardinon, J. B. Lessing et al., "Organ-specific autoantibodies are possible markers for reproductive failure: a prospective study in an in-vitro fertilization-embryo transfer programme," Human Reproduction, vol. 11, no. 8, pp. 1627-1631, 1996.

[114] K. Haller, A. Salumets, and R. Uibo, "Anti-FSH antibodies associate with poor outcome of ovarian stimulation in IVF," Reproductive BioMedicine Online, vol. 16, no. 3, pp. 350-355, 2008.

[115] N. G. Morgenthaler, S. C. Ho, and W. B. Minich, "Stimulating and blocking thyroid-stimulating hormone (TSH) receptor autoantibodies from patients with Graves' disease and autoimmune hypothyroidism have very similar concentration, TSH receptor affinity, and binding sites," The Journal of Clinical Endocrinology and Metabolism, vol. 92, no. 3, pp. 1058-1065, 2007.

[116] S. V. Shatavi, B. Llanes, and J. L. Luborsky, "Association of unexplained infertility with gonadotropin and ovarian antibodies," American Journal of Reproductive Immunology, vol. 56, no. 5-6, pp. 286-291, 2006.

[117] G. L. Warren, L. O’Farrell, K. R. Rogers, K. M. Billings, S. P. Sayers, and P. M. Clarkson, "CK-MM autoantibodies: prevalence, immune complexes, and effect on CK clearance," Muscle \& Nerve, vol. 34, no. 3, pp. 335-346, 2006.

[118] I. Kligman and Z. Rosenwaks, "Differentiating clinical profiles: predicting good responders, poor responders, and hyperresponders," Fertility and Sterility, vol. 76, no. 6, pp. 1185-1190, 2001.

[119] M. Cutolo, A. Sulli, S. Capellino et al., "Sex hormones influence on the immune system: basic and clinical aspects in autoimmunity," Lupus, vol. 13, no. 9, pp. 635-638, 2004.

[120] F. Tanriverdi, L. F. Silveira, G. S. MacColl, and P. M. Bouloux, "The hypothalamic-pituitary-gonadal axis: immune function and autoimmunity," The Journal of Endocrinology, vol. 176, no. 3, pp. 293-304, 2003.

[121] M. Narayanan, P. S. Murthy, S. A. Munaf, L. C. Shah, and M. D. Kini, "Antiovarian antibodies and their effect on the outcome of assisted reproduction," Journal of Assisted Reproduction and Genetics, vol. 12, no. 9, pp. 599-605, 1995.

[122] K. A. Hess, L. Chen, and W. J. Larsen, "The ovarian blood follicle barrier is both charge- and size-selective in mice," Biology of Reproduction, vol. 58, no. 3, pp. 705-711, 1998.

[123] G. N. Clarke, C. Hsieh, S. H. Koh, and M. N. Cauchi, "Sperm antibodies, immunoglobulins, and complement in human follicular fluid," American Journal of Reproductive Immunology, vol. 5, no. 4, pp. 179-181, 1984.

[124] C. Glister, N. P. Groome, and P. G. Knight, "Bovine follicle development is associated with divergent changes in activinA, inhibin-A and follistatin and the relative abundance of different follistatin isoforms in follicular fluid," The Journal of Endocrinology, vol. 188, no. 2, pp. 215-225, 2006.

[125] G. Lambert-Messerlian, A. Taylor, L. Leykin et al., "Characterization of intrafollicular steroid hormones, inhibin, and follistatin in women with and without polycystic ovarian syndrome following gonadotropin hyperstimulation," Biology of Reproduction, vol. 57, no. 5, pp. 1211-1216, 1997.

[126] A. M. Hussein and F. J. Bourne, "Immunoglobulin concentrations in pig follicular fluid," International Journal of Fertility, vol. 29, no. 1, pp. 54-57, 1984.

[127] T. Forges, P. Monnier-Barbarino, F. Guillet-May, G. C. Faure, and M. C. Béné, "Corticosteroids in patients with antiovarian antibodies undergoing in vitro fertilization: a prospective pilot study," European Journal of Clinical Pharmacology, vol. 62, no. 9, pp. 699-705, 2006.

[128] A. Turi, S. R. Giannubilo, S. Zanconi, A. Mascetti, and A. L. Tranquilli, "Preconception steroid treatment in infertile women with antithyroid autoimmunity undergoing ovarian stimulation and intrauterine insemination: a double-blind, randomized, prospective cohort study," Clinical Therapeutics, vol. 32, no. 14, pp. 2415-2421, 2010.

[129] E. S. Pires, F. R. Parikh, P. V. Mande, S. A. Uttamchandani, S. Savkar, and V. V. Khole, "Can anti-ovarian antibody testing be useful in an IVF-ET clinic?" Journal of Assisted Reproduction and Genetics, vol. 28, no. 1, pp. 55-64, 2011. 


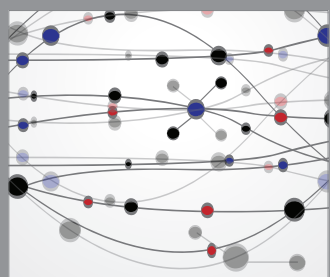

The Scientific World Journal
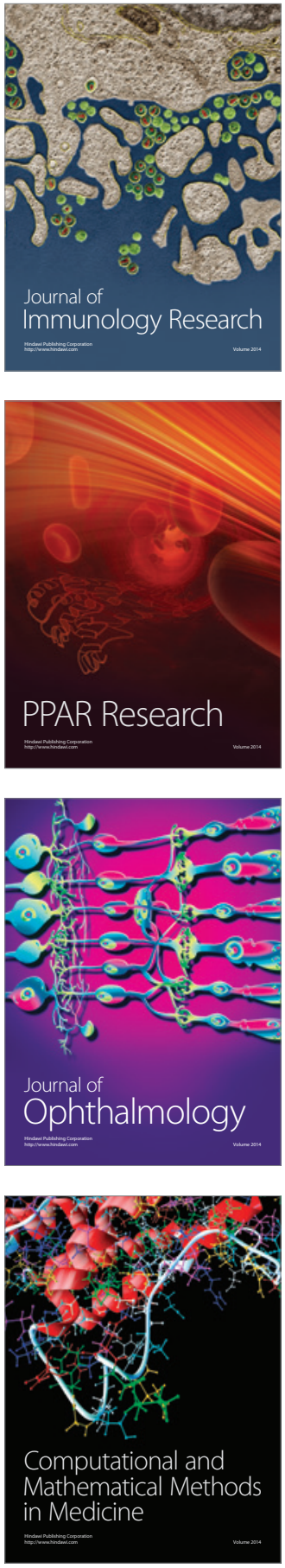

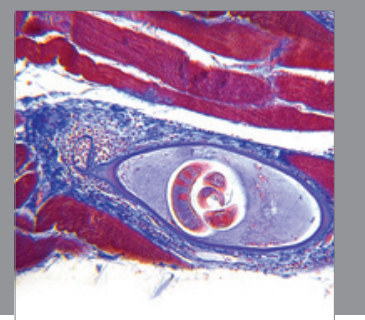

Gastroenterology

Research and Practice
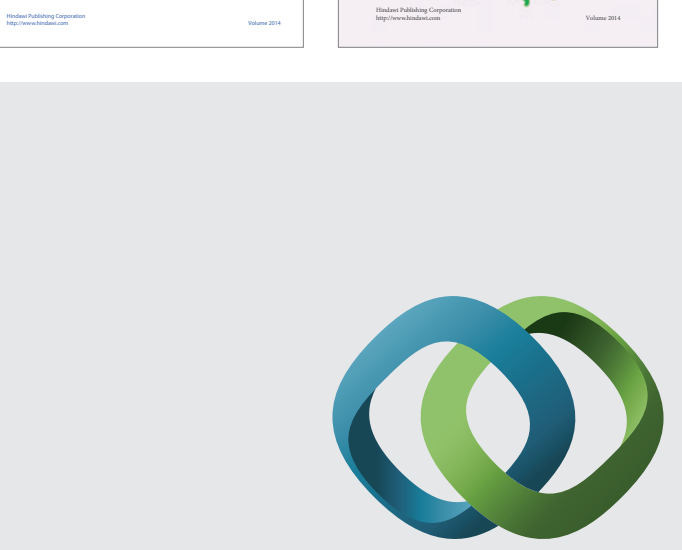

\section{Hindawi}

Submit your manuscripts at

http://www.hindawi.com
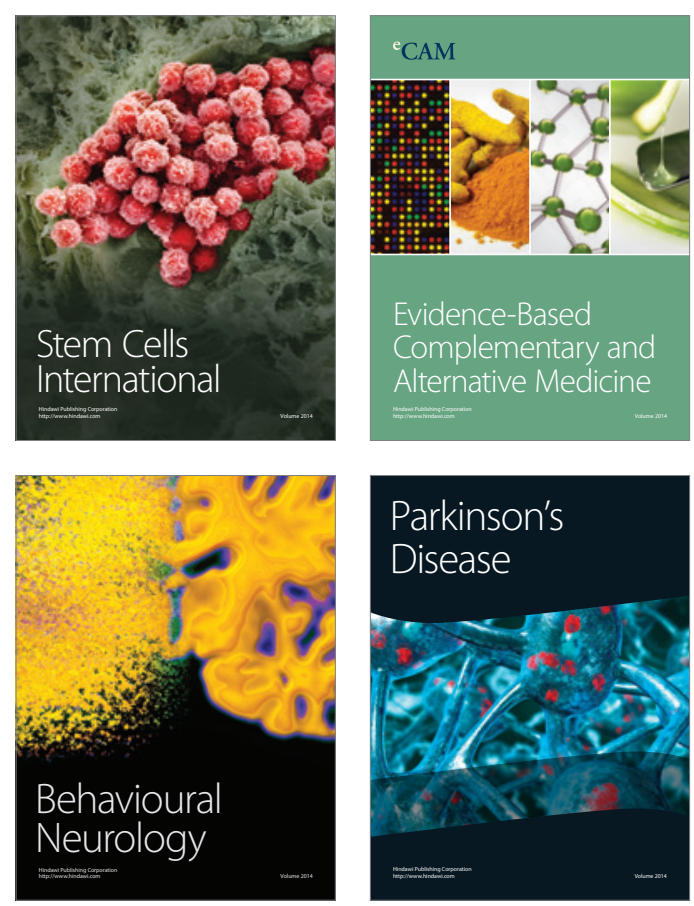

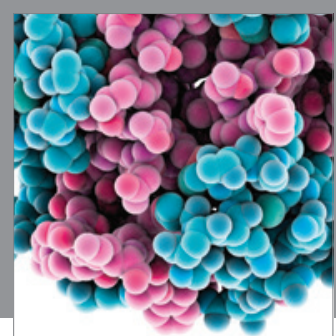

Journal of
Diabetes Research

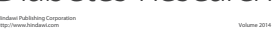

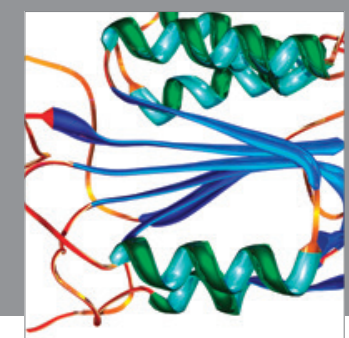

Disease Markers
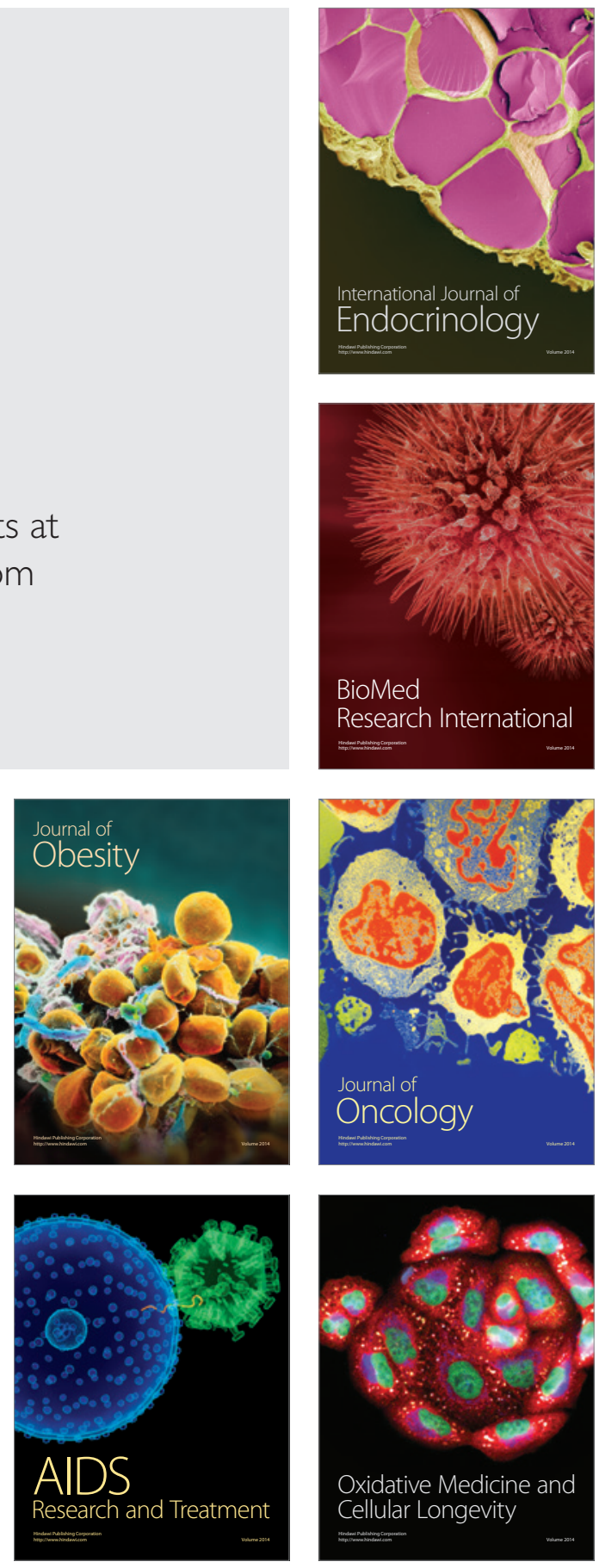